\title{
FINAL REPORT FOR AGING STUDIES OF EPDM O-RING MATERIAL FOR THE H1616 SHIPPING PACKAGE
}

\author{
T. M. Stefek \\ W. L. Daugherty \\ T.E. Skidmore
}

\section{SAVANNAH RIVER NATIONAL LABORATORY}

Materials Science \& Technology

Publication Date: June 2014

Savannah River Nuclear Solutions

Savannah River Site

Aiken, SC 29808

This document was prepared in conjunction with work accomplished under

Contract No. DE-AC09-08SR22470 with the U.S. Department of Energy. 
SRNL-STI-2014-00133

\section{DISCLAIMER}

This work was prepared under an agreement with and funded by the U.S. Government. Neither the U. S. Government or its employees, nor any of its contractors, subcontractors or their employees, makes any express or implied: 1 . warranty or assumes any legal liability for the accuracy, completeness, or for the use or results of such use of any information, product, or process disclosed; or 2. representation that such use or results of such use would not infringe privately owned rights; or 3. endorsement or recommendation of any specifically identified commercial product, process, or service. Any views and opinions of authors expressed in this work do not necessarily state or reflect those of the United States Government, or its contractors, or subcontractors. 


\section{FINAL REPORT FOR AGING STUDIES OF EPDM O-RING MATERIAL FOR THE H1616 SHIPPING PACKAGE}

\section{APPROVALS:}

T. M. Stefek

Date

Author, Materials Science and Technology

W. L. Daugherty

Date

Author, Materials Science and Technology

T. E. Skidmore

Date

Author, Materials Science and Technology

K. J. Imrich

Date

Technical Reviewer, Materials Science and Technology

K. A. Dunn

Date

$\mathrm{Pu}$ Surveillance Program Lead, Materials Science and Technology

G. T. Chandler

Date

Manager, Materials Science and Technology

P. J. French

Date

Reservoir Systems Engineering 


\section{Revision Log}

Document No. $\quad$ SRNL-STI-2014-00133

Rev. No. 0

\section{Document Title FINAL REPORT FOR AGING STUDIES OF EPDM O-RING MATERIAL FOR THE H1616 SHIPPING PACKAGE}

$\underline{\text { Rev. \# Page \# Description of Revision }}$

0 all Original document
Date

$6 / 26 / 2014$

\section{Acronyms}

\begin{tabular}{|c|c|}
\hline ANSI & American National Standards Institute \\
\hline CSR & compression stress relaxation \\
\hline $\mathrm{CV}$ & containment vessel \\
\hline DOE & Department of Energy \\
\hline EPDM & ethylene propylene diene monomer \\
\hline HAC & hypothetical accident conditions \\
\hline $\mathrm{NCT}$ & normal conditions of transport \\
\hline NNSA & National Nuclear Security Administration \\
\hline SRNL & Savannah River National Laboratory \\
\hline SRS & Savannah River Site \\
\hline TTS & time temperature superposition \\
\hline
\end{tabular}




\section{SUMMARY}

This is a final report for tasks carried out per Task Technical Plan SRNL-STI-2011-00506 [1]. A series of tasks/experiments were performed at the Savannah River National Laboratory (SRNL) to monitor the aging performance of ethylene propylene diene monomer (EPDM) O-rings used in the H1616 shipping package. The test data provide a technical basis to extend the annual maintenance of the EPDM O-rings in the H1616 shipping package to two years and to predict the life of the seals at bounding service conditions.

Baseline O-ring properties were found consistent with O-ring specifications. O-rings were aged at elevated temperature for up to 2 years, and tested for degradation in mechanical properties, compression stress relaxation (CSR) behavior, and leak performance.

Mechanical properties of aged O-rings show significant degradation can occur, but an inert atmosphere (argon backfill) will greatly reduce the rate of degradation.

The CSR behavior of H1616 shipping package O-rings was evaluated to develop an aging model. O-ring segments were aged at temperatures from $175^{\circ} \mathrm{F}$ to $350{ }^{\circ} \mathrm{F}$. Samples aging at the three highest temperatures reached a failure criterion of $90 \%$ loss of sealing force, while samples at the two lower temperatures did not. These collective data were used to develop a predictive model for extrapolation of CSR behavior to relevant service temperatures $\left(\sim 152^{\circ} \mathrm{F}\right.$ and below). This initial model indicates a service life of $\sim 5$ years can be expected at $152{ }^{\circ} \mathrm{F}$ (peak O-ring temperature at Normal Conditions of Transport [NCT]), with longer lifetimes expected at more realistic service conditions. This range is consistent with that suggested by available literature data, which largely derive from mechanical property and CSR behavior.

O-rings were aged in three H1616-1 Containment Vessels (CV) at temperatures ranging from 160 to $300{ }^{\circ} \mathrm{F}$. The vessels were helium leak tested initially and were re-tested periodically to determine if they continued to meet the leak-tight criterion defined in ANSI standard N14.5-97 $\left(<1 \mathrm{E}-07 \mathrm{std} \mathrm{cc}\right.$ air/sec). The vessels aging at $160^{\circ} \mathrm{F}$ and at $235^{\circ} \mathrm{F}$ remained leak-tight after 2 years at temperature. The inner O-ring installed in the vessel aged at $300{ }^{\circ} \mathrm{F}$ was leak-tight and would reseal at 174 days, but would not reseal after 196 days. The outer O-ring installed in this vessel remained leak-tight for 253 days.

The vessel tests provide a solid demonstration that the H1616 O-rings will remain leak-tight at temperatures up to $235^{\circ} \mathrm{F}$ for periods up to 2 years. Significantly longer periods of leak-tight service are expected at the lower temperatures actually experienced in service. The predictive model developed from the CSR data indicates a service life of $\sim 5$ years at $152^{\circ} \mathrm{F}$. Although the relationship between CSR behavior and leak-tight performance has not been established for this design, CSR predictions are conservative relative to leak-tight performance at 235 and $300^{\circ} \mathrm{F}$.

Based on the collective data presented in this report, it is recommended that the maintenance interval for the H1616 package be extended from 1 year to 2 years. These data further suggest that a maintenance interval up to 5 years might be justifiable. However, additional testing is recommended if maintenance extension beyond 2 years is desired. 


\section{BACKGROUND}

The H1616 is a certified "Type B" package for the transport of radioactive tritium reservoirs by the Department of Defense (DoD), United Kingdom (UK) Atomic Weapons Establishment (AWE), and Authorized Users (Savannah River Site (SRS), Pantex), Figure 1 [2]. The H1616 package was initially designed and produced by Sandia National Laboratory and was first certified in 1992. The packages are re-certified every 5 years by DOE/NNSA/Packaging Certification Division. There are two variations of the package, designated H1616-1 and H16162, which are of essentially the same design, except the H1616-2 has a slightly thicker containment vessel wall and has an option feature to include a getter between the two EPDM Orings. Both H1616-1 and H1616-2 utilize the same O-ring seal design.

Aluminum packing material used to position the tritium reservoir is added to the $\mathrm{CV}$ which is constructed of Type 304 stainless steel. The CV is placed inside a 16 gallon stainless steel drum (Figure 1). Two EPDM O-rings are housed between the CV lid and body and are used to seal each containment vessel. The seals are compressed nominally $25 \%(+/-3 \%)$ in concentric face seal grooves with a surface finish of $32 \mu$ inches or 32 RMS. No significant stretch is imposed, and no seal lubricant is used on the O-rings. All containers undergo annual re-verification testing, including containment vessel leak testing to verify leak-tightness to $<1 \mathrm{E}-07 \mathrm{ref} \mathrm{cc} / \mathrm{sec}$ air as per ANSI N14.5 [3].

\section{H1616}

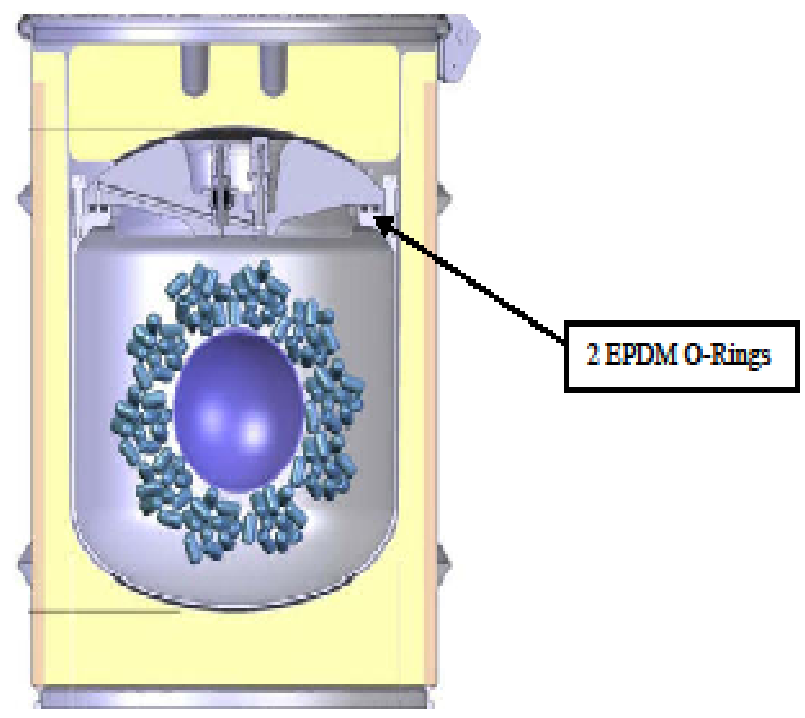

Figure 1. H1616 container showing O-ring location 
The H1616 O-ring compound formulation cited in Reference 2 was assumed to be the current formulation at the beginning of this study and as listed in Reference 4 (EPDM aging data review). However, other documents [5] indicate that the O-ring formulation is currently based on Royalene ${ }^{\circledR} 580 \mathrm{HT}$ due to availability issues with Nordel ${ }^{\circledR} 1440 / 1470$ polymers in 1999 .

The following EPDM compounds are currently approved for the H1616 seals per Sandia specification SS395668: SR792B-80 (Stillman Seal), XP-0375 (Wynn's Precision, Inc.) and EXP-5225A (R\&S Processing Co., Inc.). Both older and current formulations are given in Table 1. The effective date of the compound change is unknown to SRNL. SS395668 Change Issue K (original formulation) was effective in 04/06, with Change Issue L (current formulation) effective on $05 / 10$. The cure date shown on the packaging of the O-rings provided to SRNL for testing is L08 (MFG code=BJY, lot\#23881, December 2008). The O-ring composition was not analyzed or verified as part of this task.

Table 1. H1616 EPDM seal compound SS\#395668 [2, 5]

Ingredients

\begin{tabular}{|c|c|c|c|}
\hline & Original Formulation (phr) & Current Formulation (phr) & Approved Alternate \\
\hline Nordel 1470 & 100 & 100 & \\
\hline Royalene 580 HT & 5 & 5 & Zinc oxide \\
\hline Zic Stick 85 & 40 & 40 & N-550 carbon black \\
\hline N-990 carbon black & 25 & 25 & Agerite Resin D (RT \\
N-539 carbon black & 12 & 12 & \begin{tabular}{c} 
Vanderbilt) \\
\hline Dicup 40C
\end{tabular} \\
\hline $\begin{array}{c}\text { Flectol TMQ or } \\
\text { Flectol H }\end{array}$ & 2 & 10 & $\begin{array}{c}\text { PLB-5405 (Synthetic } \\
\text { Products), 13.3 phr }\end{array}$ \\
\hline \begin{tabular}{c} 
SR-350 Sartomer \\
\hline
\end{tabular}
\end{tabular}

$\mathrm{phr}=$ parts per hundred rubber (by weight)

Physical/Mechanical Properties

\begin{tabular}{|l|l|}
\hline Thickness, inches & $0.21+/-0.005$ \\
\hline Hardness, Shore A & $78+/-5$ \\
\hline Tensile Strength, psi & 1200 minimum \\
\hline Elongation, percent & 100 minimum \\
\hline Compression Set & $12 \% \max (70$ hrs @ $125 \mathrm{C})$ \\
\hline
\end{tabular}

The O-rings in the H1616-1 and the H1616-2 vessels are of slightly different major diameter but they have the same thickness, experience no stretch, and are compressed the same amount in service. The O-rings see essentially the same environmental conditions. Therefore, only the H1616-1 vessel was used in these tests, and the results are considered equivalent for H1616-2 vessels. 
The safety analysis report for the H1616 package describes the following environmental conditions [2]. The service temperature range for the $\mathrm{H} 1616$ vessel is $-40{ }^{\circ} \mathrm{F}$ to $169{ }^{\circ} \mathrm{F}$. The NCT temperature $\left(169^{\circ} \mathrm{F}\right)$ is based on an ambient temperature of $100^{\circ} \mathrm{F}$ with solar heating. The maximum temperature at the flange closest to the O-rings is $152^{\circ} \mathrm{F}$ with solar heating and $116^{\circ} \mathrm{F}$ in the shade. Therefore, the maximum temperature judged to be most applicable to the O-rings is $152{ }^{\circ} \mathrm{F}$. This is recognized to be a non-chronic condition, and typical seal temperatures are expected to be lower. Bounding radiation dose rates for the H1616 O-rings are not significant relative to seal performance.

The inner O-ring of the H1616-1 and H1616-2 without getter is credited as a containment boundary for transport purposes. For the H1616-2 with getter, the outer O-ring is credited as a containment boundary for transport purposes. The leak rate criterion for the EPDM seals is leaktight per ANSI N14.5, or $<1 \mathrm{E}-07 \mathrm{ref} \mathrm{cc} / \mathrm{sec}$ air, which is performed at ambient temperature. A nitrogen or argon backfill gas is specified for the H1616 containment vessels. No lubricant is used for the O-rings.

\section{SUMMARY OF BASELINE AGING DATA REVIEW}

A literature/data review was performed on EPDM seals as part of this task. Focus was given to data believed to be the most relevant to sealing applications similar to the H1616 application. An abundance of aging data exists for EPDM elastomer in other applications, including outdoor weathering, roofing membranes and seals in fluid service, but these were not considered appropriate for comparison. A summary of the literature/data review performed is provided. These data generally involve testing of mechanical and CSR properties, with some data on leaktightness and oxygen consumption rates. Additional details are given in Reference 4.

Comparison of aging data for different EPDM compounds from multiple sources using varying approaches and failure parameters is complex. Being hydrocarbon-based, EPDM is known to be sensitive to oxidation, therefore typically requiring antioxidants in the formulation. However, once the antioxidant is depleted or consumed, the polymer oxidation rate will likely increase, possibly resulting in accelerated degradation as indicated by loss of mechanical properties and sealing force.

A summary of the EPDM seal lifetimes observed or predicted at various temperatures from different references is given in Figure 2. Direct comparison is difficult as the basis for performance or failure in each reference varies. Data points represented by solid symbols (references 13, 15 and 21 cited in the literature/data review) are not actual failures as defined by CSR or leakage, but represent samples removed from test prior to failure.

The trend line shown in Figure 2 is a lower bound of all of the reviewed failure data. This is intended to show conservative lifetimes that might be predicted from the available data, though actual lifetimes could vary. At $76^{\circ} \mathrm{C}\left(169^{\circ} \mathrm{F}\right)$, the H1616 NCT peak temperature, the trend line suggests a lifetime of $\sim 4.2$ years. At $67^{\circ} \mathrm{C}\left(152{ }^{\circ} \mathrm{F}\right)$, the peak temperature closest to the O-rings, the trend line suggests a lifetime of $\sim 5.8$ years. At $47^{\circ} \mathrm{C}\left(\sim 116^{\circ} \mathrm{F}\right)$, the peak O-ring temperature in shade $\left(100^{\circ} \mathrm{F}\right.$ ambient $)$, the trend line suggests a lifetime of $\sim 16.4$ years. 


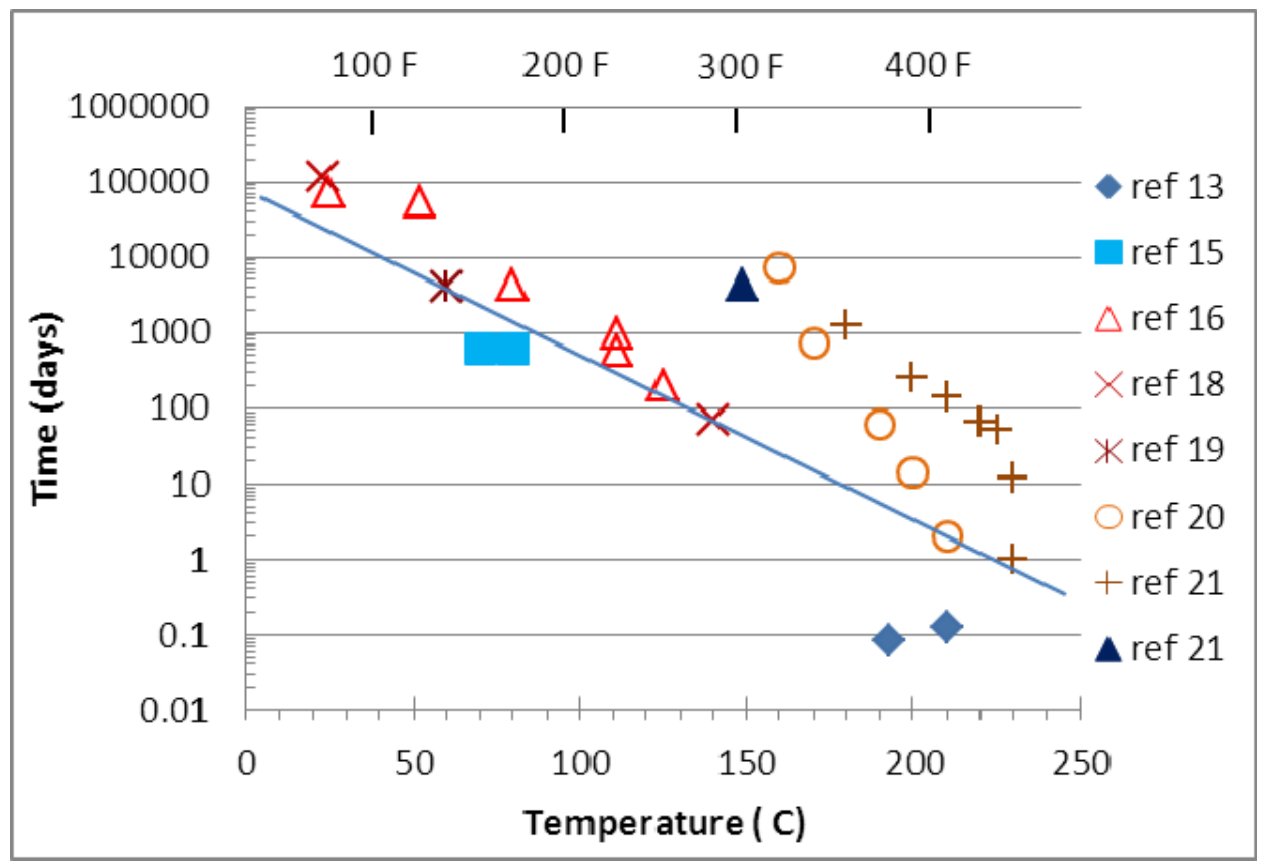

Figure 2. EPDM O-ring lifetime data from literature references [4]

The data review was primarily focused on long-term performance of EPDM seals at elevated temperatures consistent with NCT. The performance of aged seals at Hypothetical Accident Conditions (HAC) such as fire or low temperature extremes was not part of the current SRNL study. With a low glass transition temperature $\left(\sim-58^{\circ} \mathrm{F}\right)$, EPDM seals have significant margin at $-40^{\circ} \mathrm{F}$ (typical transport regulatory condition) such that low temperature performance even after significant aging is likely acceptable. The low temperature performance of aged seals has not been widely studied. However, this is not considered a major concern for the H1616 package since low temperature conditions are not anticipated in normal service and the degradation observed/predicted within 2 years at bounding conditions is not severe.

\section{EXPERIMENTAL APPROACH}

Despite the favorable O-ring performance identified in the literature review, there is no substitute for real-time aging at realistic or bounding conditions. Therefore, the periodic examination and testing of actual seals from a select group of H1616 shipping packages aged at bounding conditions were used to validate assumptions and make predictions based on accelerated-aging methodology. Such examinations cannot predict time to failure until failure is actually observed, but advance notice of degradation may be provided. A description of the tests performed is included. 


\section{Baseline O-Ring Characterization}

Confirmatory measurements were performed on a limited number of O-ring samples to verify the O-ring physical and mechanical properties are consistent with the O-ring specification. Thickness measurements were verified at four equally-spaced points along the circumference in both top-to-bottom and side-to-side orientations. Hardness measurements were verified with a calibrated Durometer Shore Hardness tester measured on the top of the O-ring at 5 points along the circumference using two scales, Durometer Shore A (per specification) and Durometer Shore $\mathrm{M}$ for comparison. Durometer Shore M scale (microhardness) is required per ASTM D2240 for O-rings less than 0.25 inch thick. M-scale and A-scale values tend to be very close but there is no direct conversion.

\section{H1616 Vessel Aging and Leak Testing ${ }^{1}$}

Vessel aging and leak tests were performed using three full-size containment vessels. Since aging at room temperature is not expected to produce leak failure in the time allotted for testing (two years), these test CVs were aged at conditions that bound operating temperatures with the intent to drive the O-rings to failure within the 2 year test period. This approach used actual vessels and the leak-tight acceptance criterion for service. Failure of the $\mathrm{CV}$ seal is a leak rate greater than the leak-tight criterion of $1 \mathrm{E}-07 \mathrm{cc} / \mathrm{sec}$ dry air at $25{ }^{\circ} \mathrm{C}$ and 1 atm pressure differential. The vessels were heated externally such that O-ring temperatures were maintained at either $160^{\circ} \mathrm{F}, 235^{\circ} \mathrm{F}$, or $300^{\circ} \mathrm{F}$. The use of three temperatures allows extrapolation of results to support life prediction model development. These temperatures are based on bounding service temperatures and bounding "continuous" temperature ratings as indicated from typical EPDM compounds. Again, the $160^{\circ} \mathrm{F}$ temperature is bounding for normal service as it accounts for solar heating superimposed on a $100{ }^{\circ} \mathrm{F}$ ambient temperature, neither of which are chronic conditions.

Each CV was placed in a round metal pan within a test stand (Figure 3). Two Watlow ${ }^{\circledR}$ heaters, 6 inches wide $\mathrm{x} 20$ inches long were wired in series and wrapped around the upper half of the vessel. These heaters provided 300 watts $(2.5 \mathrm{amps})$ of heating to the vessel. 24 layers of aluminum foil were placed between the heater and the vessel OD to accommodate the heater length without overlap. The foil, heaters and 1 layer of silica insulation were secured to the vessel with band clamps. Additional silica insulation was added to the side, top and bottom of the vessel to help regulate vessel temperature. Additional band clamps held the side insulation in place. Ring supports, bolts, and braces were fabricated to hold the vessel secure in the stand (Figure 4).

\footnotetext{
${ }^{1}$ Although the Task Technical Plan originally identified the leak testing as Scoping data, it was performed in accordance with Technical Baseline data requirements at the request of the customer (Paul Lari, Sandia National Lab, December 2011).
} 


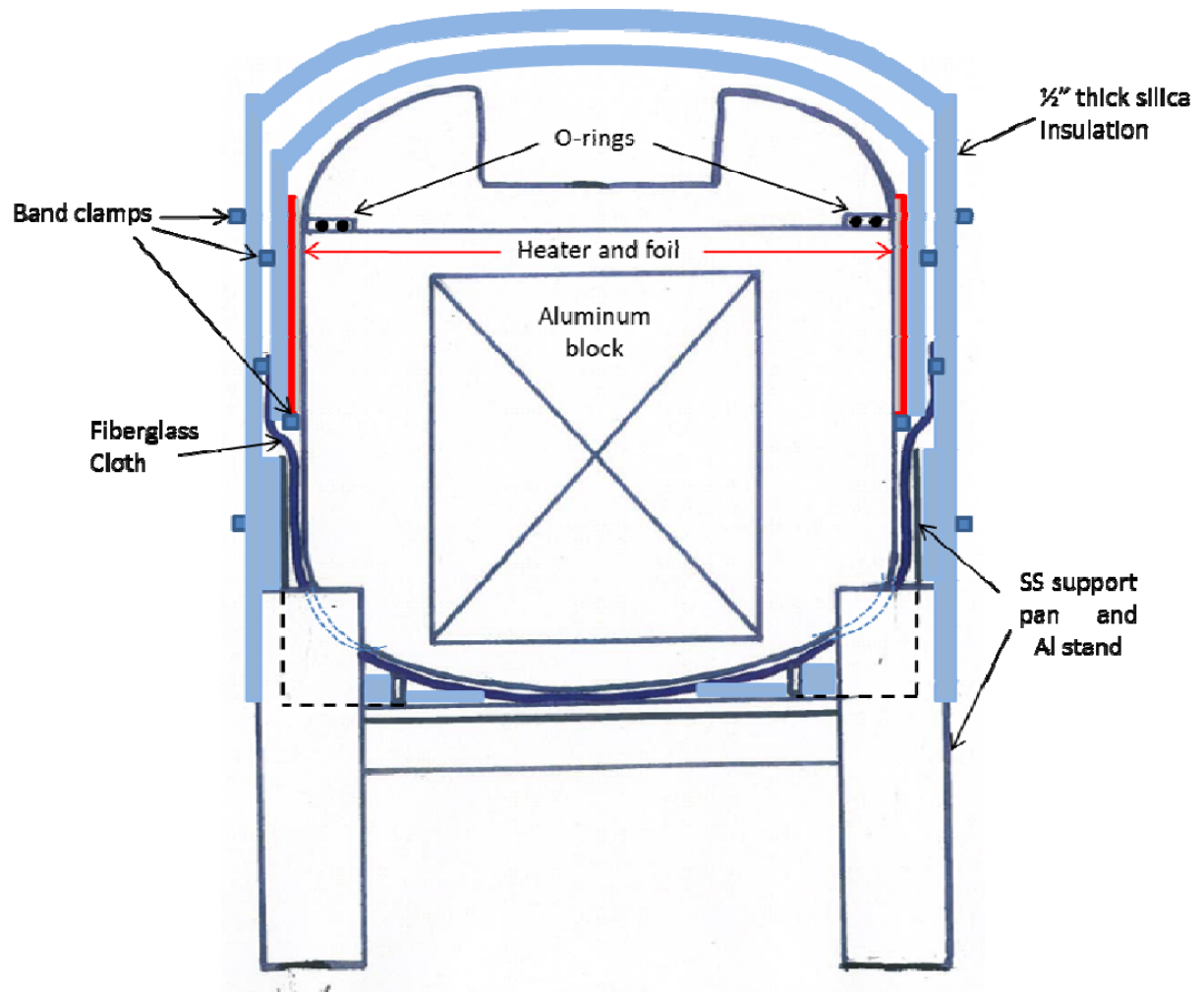

Figure 3. Cross section sketch of vessel and insulation arrangement

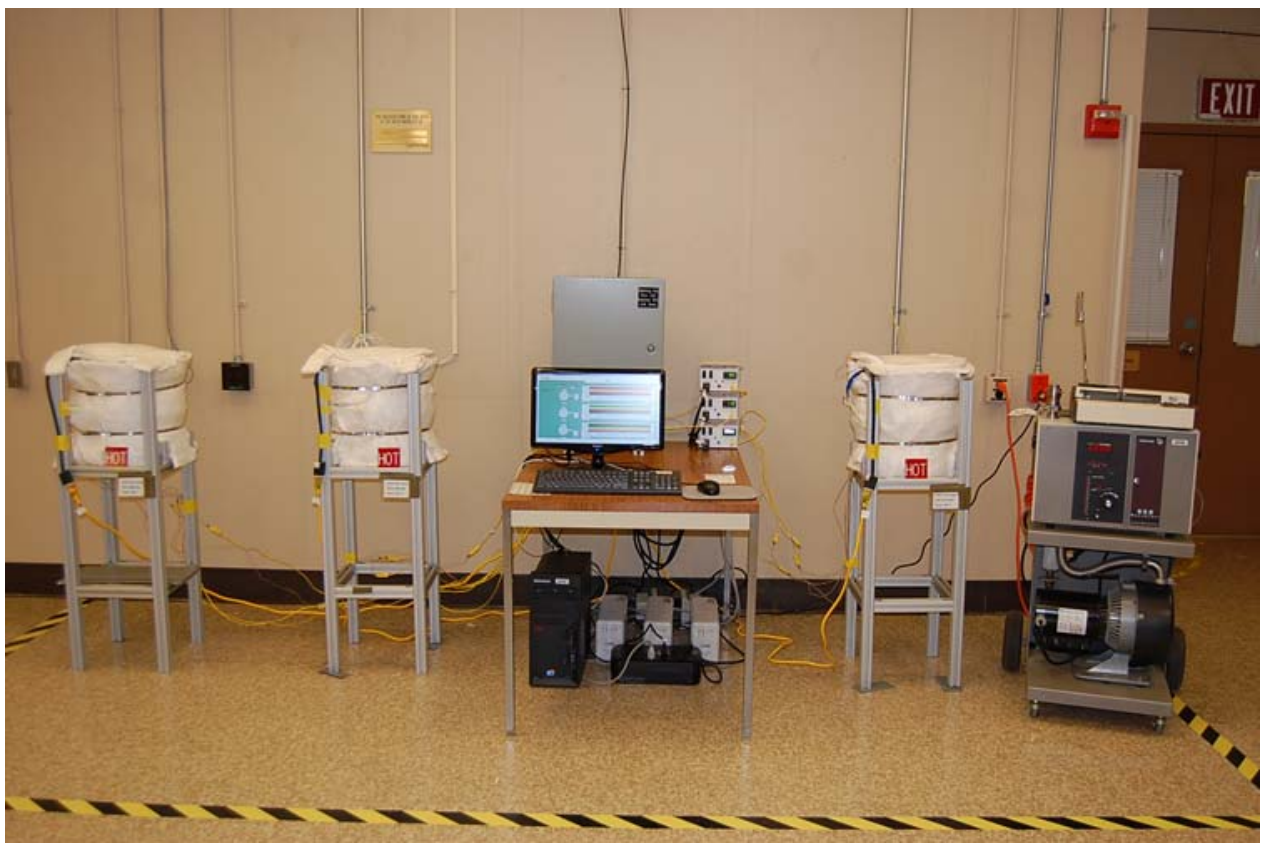

Figure 4. Containment vessel leak test setup 
Four thermocouples were placed at 90 degree intervals between the aluminum foil and the outside of vessel, approximately 1.5 inches from the top surface of the CV lid. Thermocouples were verified with a calibrated Dry Well Calibrator and thermocouple reader. The heaters were controlled by a LabView ${ }^{\circledR}$ software program. One thermocouple from each vessel was used to control the heater, while two additional thermocouples provided assurance that the vessel was heating uniformly. The fourth thermocouple provided a signal to an over-temperature controller which prevented an unplanned thermal excursion.

Tritium Packaging Operations personnel replaced the sample valve O-ring, the sample fitting Oring, and the hex head plug O-ring on all three vessels after the trial runs and before new CV Orings were installed to begin testing. The new $\mathrm{CV}$ inner and outer O-rings were installed by SRNL personnel.

A thin strip of 0.005 inch thick stainless steel shim was placed on the vessel flange between the O-rings to prevent a possible metal-to-metal seal from masking the leak behavior of the O-rings. Initial tests were performed to show permeation (gradual increase in detector response over time) to prove helium access to/through the O-rings. This step eliminates the possibility of false positive results (no leakage path). In addition, vessel O-ring temperature/vessel gradient heat-up trials were performed to determine the correct temperature control settings, as shown in Table 2.

Table 2. Vessel O-ring/control temperature comparison

\begin{tabular}{|c|c|c|c|}
\hline Vessel Body ID & Vessel Lid ID & $\begin{array}{c}\text { Desired O-ring Aging } \\
\text { Temperature }\left({ }^{\circ} \mathbf{F}\right)\end{array}$ & $\begin{array}{c}\text { Vessel Exterior Control } \\
\left.\text { Temperature ( }{ }^{\circ} \mathbf{F}\right)\end{array}$ \\
\hline 13784 & 13774 & 160 & 165 \\
\hline 11274 & 11296 & 235 & 241 \\
\hline 13772 & 13896 & 300 & 313 \\
\hline
\end{tabular}

An aluminum block ( 8 inches diameter $\mathrm{x} 10$ inches long) was placed inside each vessel to reduce the amount of gas space and facilitate leak testing.

Argon (at least 99.99\%) was used as a backfill gas. Leak tests were performed periodically, after the vessel cooled down to room temperature. Leak-tightness was verified per ANSI N14.5-97 with a hood test performed by a certified Level II Leak Test Specialist. The vessel was bagged, and the vessel interior and exterior were evacuated and backfilled with helium (Figure 5). A helium mass spectrometer leak detector was connected to the test volume between the two Orings to detect leakage from either O-ring. When necessary, vessel connections were reconfigured to test each O-ring individually. 


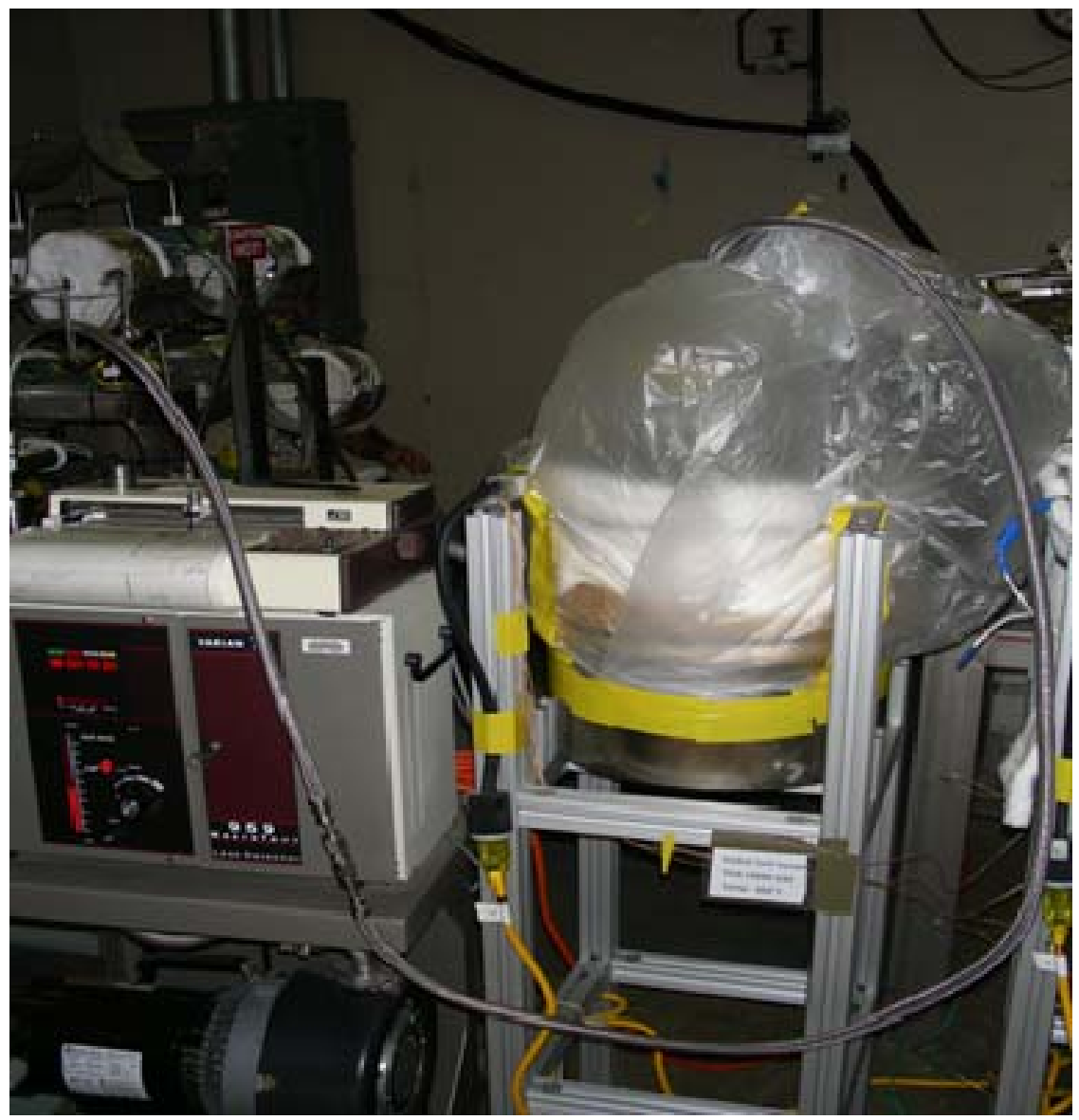

Figure 5. Hood test on containment vessel

The test CV's were opened periodically in conjunction with leak testing, keeping the same Orings in place. These openings were intended to prevent artificial "sticking" of the O-rings, which could provide a false positive result, and provide a more realistic representation of actual in-service practice. This behavior has been observed in other studies, particularly at higher aging temperatures [6]. 


\section{Compression Stress Relaxation Testing}

Compression stress relaxation (CSR) tests were performed on the H1616 O-rings at several aging temperatures to develop an aging model based on sealing force decay. In the absence of fluid or significant radiation exposure, thermo-oxidative aging and sealing force decay is expected to be the most relevant degradation mechanism for the H1616 O-rings. CSR tests are a common industry method for evaluating the mechanical performance of seals over time at various aging temperatures. CSR tests were performed per ASTM D6147, using the periodic measurement approach.

A single H1616 O-ring was carefully cut into several segments $\sim 0.75$ inch long, with three segments placed into each CSR jig (Shawbury-Wallace type). The CSR jigs were initially developed to compress large disc samples, but several studies have shown that diffusion-limited oxidation effects are possible with larger samples, and disc samples do not ideally represent actual O-ring behavior, even if made of the same elastomer compound [7]. Three segments were selected to balance the contact area of the compression platens and the surface area of the exposed material. The segments were then compressed approximately $25 \%$ from 0.21 inch cross-section thickness to $\sim 0.1575$ inch as in the H1616 design. A fabricated shim was used to verify compression.

The jigs with compressed samples were placed into aging ovens, with three jigs per temperature for repeatability. Aging temperatures $\left(175^{\circ} \mathrm{F}, 235^{\circ} \mathrm{F}, 270^{\circ} \mathrm{F}, 300^{\circ} \mathrm{F}\right.$ and $\left.350^{\circ} \mathrm{F}\right)$ were selected to bound expected normal service temperatures and to challenge the seals within a reasonable aging period. Excessive aging temperatures should be avoided, but failures must be observed in order to predict failure at more reasonable service temperatures. Prior to compressing samples in the jigs, the break force for each jig was determined using the relaxometer. The break force is subtracted from later total force measurements to give sealing force measurements only.

Upon initial compression but prior to aging, the compressed jigs were placed into the relaxometer to obtain a baseline sealing force measurement at room temperature. During aging, the CSR jigs were periodically removed from the aging ovens and placed in the relaxometer (Figure 6) for measurement of sealing force, which is the force required to deflect the compressed seals approximately 0.0001-0.0002 inch. As the elastomer relaxes and ages over time, this counterforce value is reduced. During periodic sealing force measurements, five sequential readings were typically taken, with time and temperature of the jig monitored. Measurements are taken as quickly as possible to capture the sealing force at the aging temperature, rather than waiting for the fixture to cool to room temperature. CSR values can be taken at any temperature, but should be taken as close to the aging temperature as possible for direct comparisons and interpretation of sealing behavior at the actual temperature of interest. Using the average sealing force value for all five measurements per test period minimizes concern over sealing force fluctuations with temperature due to cooling effects. 


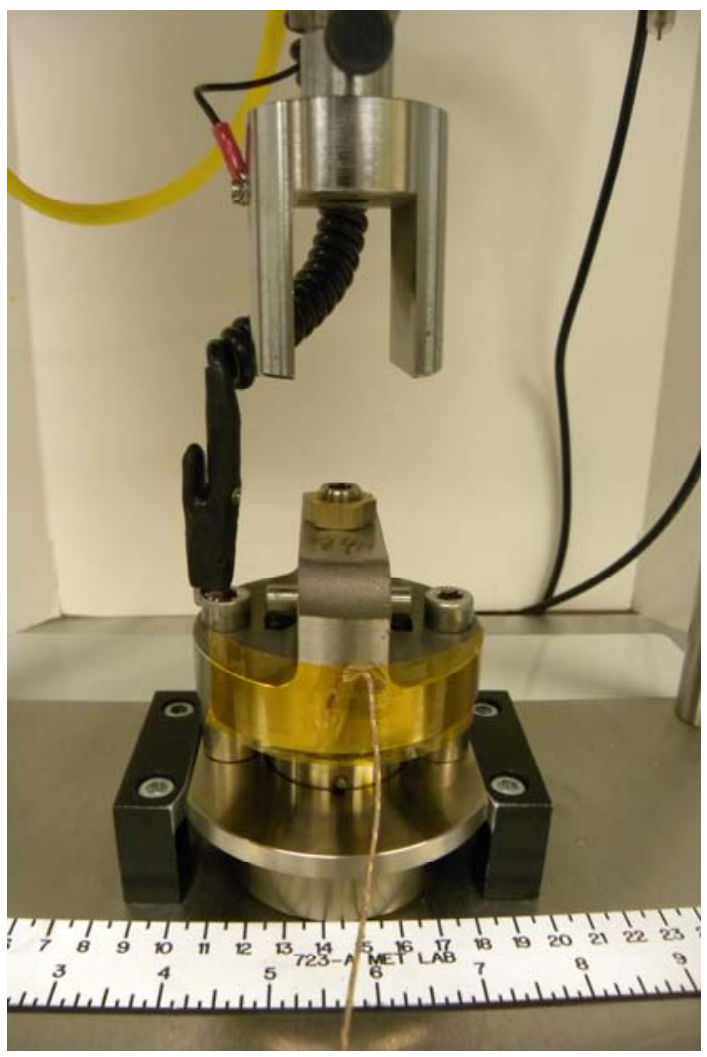

Figure 6. CSR jig in relaxometer for sealing force measurement

The main goal of the CSR tests is to age the seals to a significant degradation point (loss of sealing force) at multiple temperatures, which allows development of an aging model based on Arrhenius theory and Time Temperature Superposition (TTS) of the collective data. Ideally, it is desirable for failure to be reached at all aging temperatures within the planned aging period for model development. For CSR testing, a $90 \%$ loss in sealing force $\left(\mathrm{F} / \mathrm{F}_{\mathrm{o}}=0.10\right)$ was selected as the failure or end-of-life parameter. This parameter has been used for other critical seal applications such as nuclear weapon components [8]. However, it is emphasized that CSR failure does not inherently mean that the seal is no longer functional or leak-tight. The use of $90 \%$ sealing force loss leaves $10 \%$ of the initial sealing force remaining for margin. This is expected to be more than sufficient for most static seal designs. The relationship between CSR and leak rate has not been established for this design and was not part of the scope for this task.

One advantage of the TTS principle is that all of the data can be used in the aging model, rather than using only a few time to failure data points. Another advantage of the TTS principle is that if the same degradation mechanism exists over the full aging temperature range and at the expected service temperatures, the aging model can be translated to any temperature of interest. 


\section{RESULTS / DISCUSSION}

\section{Baseline O-Ring Characterization}

Confirmatory measurements on twelve new O-rings were performed to verify the material properties were consistent with existing published vendor data (Table 3). All O-ring thickness measurements were within the specified range of $0.21+/-0.005$ inches. All O-ring hardness measurements were within the specified range of $78+/-5$ "A" scale. Both the thickness and hardness measurements are non-destructive.

Since the tensile strength and elongation tests are destructive, a limited number of O-rings were tested using the Instron Tensile Tester. The O-rings were held in padded grips and pulled at a rate of 20 inches per minute. The O-rings tested met the specified requirements of greater than 1200 psi tensile strength, and greater than 100 percent elongation. The basis for the requirements in the O-ring specification is unknown, but the values are typical for similar compounds.

Table 3. Baseline confirmatory measurements of O-rings

\begin{tabular}{|c|c|c|c|c|c|c|}
\hline Sample ID: & $\begin{array}{c}\text { Average } \\
\text { Thickness } \\
\text { (inches) } \\
\text { (top - } \\
\text { bottom) }\end{array}$ & $\begin{array}{c}\text { Average } \\
\text { Thickness } \\
\text { (inches) } \\
\text { (side - } \\
\text { side) }\end{array}$ & $\begin{array}{c}\text { Average } \\
\text { Hardness } \\
\text { (A) }\end{array}$ & $\begin{array}{c}\text { Average } \\
\text { Hardness } \\
\text { (M) }\end{array}$ & $\begin{array}{c}\text { Tensile } \\
\text { Strength } \\
\text { (psi) }\end{array}$ & $\begin{array}{c}\text { Elongation } \\
(\%)\end{array}$ \\
\hline 1 -1 Outer & 0.2090 & 0.2120 & 80 & 80 & 2267 & 335 \\
\hline 1 -1 Inner & 0.2076 & 0.2120 & 80 & 80 & 2017 & 294 \\
\hline 2 -1 Outer & 0.2090 & 0.2123 & 80 & 80 & & \\
\hline 2 -1 Inner & 0.2085 & 0.2113 & 80 & 79 & & \\
\hline 3 -1 Outer & 0.2096 & 0.2123 & 80 & 80 & & \\
\hline 3 -1 Inner & 0.2088 & 0.2121 & 79 & 79 & & \\
\hline 4 -1 Outer & 0.2091 & 0.2118 & 80 & 77 & & \\
\hline 4 -1 Inner & 0.2089 & 0.2120 & 80 & 81 & & \\
\hline 5 -1 Outer & 0.2093 & 0.2113 & 80 & 78 & 2116 & 392 \\
\hline 5 -1 Inner & 0.2086 & 0.2126 & 80 & 79 & 2137 & 340 \\
\hline 6 -1 Outer & 0.2099 & 0.2123 & 80 & 79 & & \\
\hline 6 -1 Inner & 0.2089 & 0.2130 & 80 & 79 & & \\
\hline
\end{tabular}




\section{H1616 Vessel Aging and Leak Testing}

Three containment vessels which had seen actual service were transferred to SRNL. The vessels were known to have been fabricated per specification and were not removed from service due to any known defects or non-conformances. Initial baseline leak tests were performed on each vessel by a certified Level II Leak Test Specialist on January 3, 2012. Heating of containment vessels began at $08: 30$ on January 4, 2012 and all three reached target temperature the same day. Leak tests were performed on each vessel after one month and at varying intervals thereafter (Table 4). Each time the vessel lid was removed, a visual inspection was performed on the vessel body and lid O-ring grooves, and a visual and hardness test was performed on the inner and outer O-rings (Figure 7).

Table 4. Vessel leak test Intervals

\begin{tabular}{|c|c|c|c|}
\hline $\mathbf{3 0 0}^{\circ} \mathbf{F}$ Air & $\mathbf{3 0 0}^{\circ} \mathbf{F}$ Argon & $\mathbf{2 3 5}^{\circ} \mathbf{F}$ Argon & $\mathbf{1 6 0}^{\circ} \mathbf{F}$ Argon \\
\hline 0 & 0 & 0 & 0 \\
\hline 22 & 25 & 25 & 25 \\
\hline 43 & 47 & 108 & 109 \\
\hline 64 & 64 & 189 & 303 \\
\hline 85 & 81 & 302 & 363 \\
\hline 105 & 99 & 362 & 499 \\
\hline 127 & 127 & 401 & 595 \\
\hline 152 & 145 & 440 & 650 \\
\hline 171 & 161 & 495 & 732 \\
\hline 193 & 174 & 556 & still leak-tight \\
\hline still leak-tight & $\mathbf{1 9 6}^{*}$ & 612 & \\
\hline & 218 & 633 & \\
\hline & 234 & 679 & \\
\hline & $253^{*}$ & 732 & \\
\hline & & still leak-tight & \\
\hline
\end{tabular}

*300 ${ }^{\circ} \mathrm{F}$ Argon O-rings were leak-tight and would reseal at 174 days (inner O-ring) and 234 days (outer O-ring). The O-rings were leaktight as sealed at 196 days (inner O-ring) and 253 days (outer O-ring), but would not reseal. 


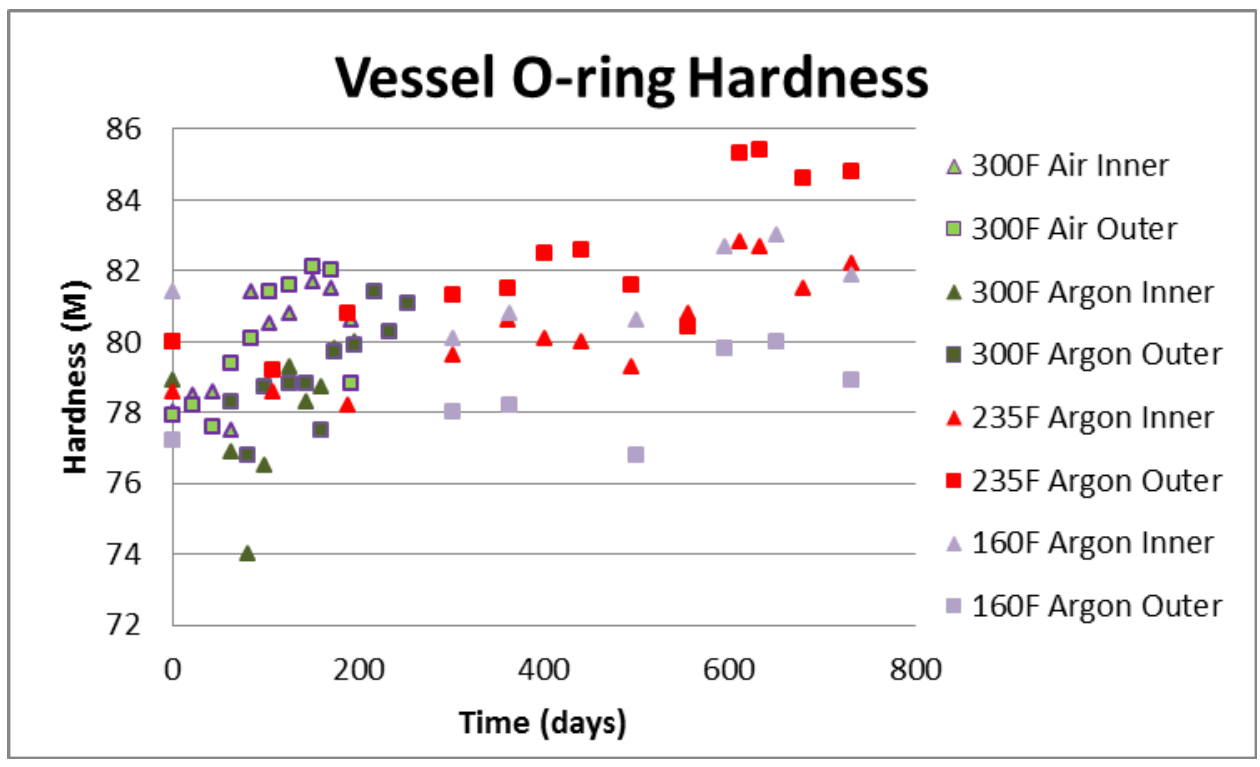

Figure 7. Hardness of O-rings in containment vessels

After $\sim 64$ days at $300{ }^{\circ} \mathrm{F}$, the O-rings became sticky and an oily residue was observed on the Orings and in the O-ring grooves. The O-rings and the O-ring grooves were cleaned using isopropyl alcohol wipes to remove the residue, and replaced in the vessel. Another leak test was performed to verify that leak-tightness was not compromised by the inspection. After 85 days at $300^{\circ} \mathrm{F}$, the inner and outer O-rings were beginning to "flatten" and lose their round shape.

After $\sim 99$ days at $235^{\circ} \mathrm{F}$, the O-rings started showing some evidence of flattening, however no oily deposits were reported on the O-rings or in the O-ring grooves until after $\sim 302$ days at temperature. As was done with the $300^{\circ} \mathrm{F}$ vessel, the O-rings and the O-ring grooves were cleaned using isopropyl alcohol wipes to remove the residue, and replaced in the vessel. Another leak test was performed to verify that leak-tightness was not compromised by the inspection.

After 303 days, the O-rings in the vessel aging at $160^{\circ} \mathrm{F}$ became a little sticky, however no residue was observed and there was no flattening of the O-rings even after 734 days.

The vessels aging at 160 and $235^{\circ} \mathrm{F}$ reached two years at temperature and maintained leaktightness throughout the period. Both of these vessels were able to reseal following the final leak test and inspection. The vessel aging at $300^{\circ} \mathrm{F}$ remained leak-tight and resealed after 174 days, then failed to reseal after 196 days at temperature. To understand the effect of oxidation due to the isolation provided by the $\mathrm{O}$-ring groove and lid design, the $300^{\circ} \mathrm{F}$ vessel was returned to test temperature with new O-rings and no backfill. This additional test successfully demonstrated no significant decrease in O-ring service life resulting from the absence of inert backfill. 


\section{Compression Stress Relaxation Testing}

CSR jigs with compressed H1616 O-ring segments were placed in aging ovens at the following temperatures in November 2011: $175^{\circ} \mathrm{F}, 235^{\circ} \mathrm{F}, 300^{\circ} \mathrm{F}$ and $350^{\circ} \mathrm{F}$. CSR measurements were recorded approximately every 30 days, depending on the aging temperature. A shim fabricated to $75 \%$ of nominal O-ring thickness ( 0.1575 inch) was used to check the degree of compression in each jig. All O-ring segments came from a single O-ring so thickness for each segment was assumed to be constant.

After aging at $350{ }^{\circ} \mathrm{F}$ for about 9 weeks, some O-ring segments in one jig were observed to be split vertically across the compressed cross-section. However, additional aging was allowed to continue. The $350{ }^{\circ} \mathrm{F}$ CSR O-ring segments reached an end-of-life condition $(90 \%$ loss in initial sealing force) in February 2012, after 11 weeks aging time.

O-ring segments that were aging at $300^{\circ} \mathrm{F}$ reached an end-of-life condition in April 2012 after $21-23$ weeks. At the end of life, samples aging at $300^{\circ} \mathrm{F}$ did not exhibit signs of cracking as observed at $350{ }^{\circ} \mathrm{F}$. The higher $350^{\circ} \mathrm{F}$ aging temperature is quite high for EPDM elastomer, which is normally rated for "continuous" service temperatures of $250-300^{\circ} \mathrm{F}$, particularly in air.

As a result of early failures at $350^{\circ} \mathrm{F}$, additional O-ring segments from the same initial O-ring were cut and placed into the same CSR jigs from the $350^{\circ} \mathrm{F}$ tests and aged at $270{ }^{\circ} \mathrm{F}$ to maximize data for aging model development. These jigs began aging at $270{ }^{\circ} \mathrm{F}$ in May 2012 and reached an end-of-life condition in February 2013 after $37-43$ weeks aging time. The $270{ }^{\circ} \mathrm{F}$ temperature was selected as an intermediate temperature between the $300^{\circ} \mathrm{F}$ and $235^{\circ} \mathrm{F}$ aging temperatures for convenience.

The CSR samples aging at $235^{\circ} \mathrm{F}$ experienced an unplanned temperature excursion in April 2013 , after reaching $\sim 75 \%$ loss in initial sealing force at about 68 weeks aging time. They were subsequently removed from further testing. New samples were prepared from the same O-ring, and were pre-aged at either $270^{\circ} \mathrm{F}$ or $300{ }^{\circ} \mathrm{F}$, in an attempt to accelerate their degradation up to $\sim 75 \%$ loss in initial sealing force. These jigs were then transferred to $235^{\circ} \mathrm{F}$ to develop the remainder of the $235^{\circ} \mathrm{F}$ force decay curve. The replacement jigs remained in test from May 2013 until March 2014.

Sealing force decay curves (CSR curves) for the original H1616 O-ring segments at aging temperatures are given in Figure 8. In these curves, the sealing force for each jig is normalized to the initial maximum sealing force. The $175^{\circ} \mathrm{F}$ CSR samples were removed from test in March 2014 following 2.3 years at aging temperature, with up to 35\% loss in initial sealing force. Sealing force decay curves for the $235^{\circ} \mathrm{F}$ accelerated replacement samples are shown in Figure 9. 


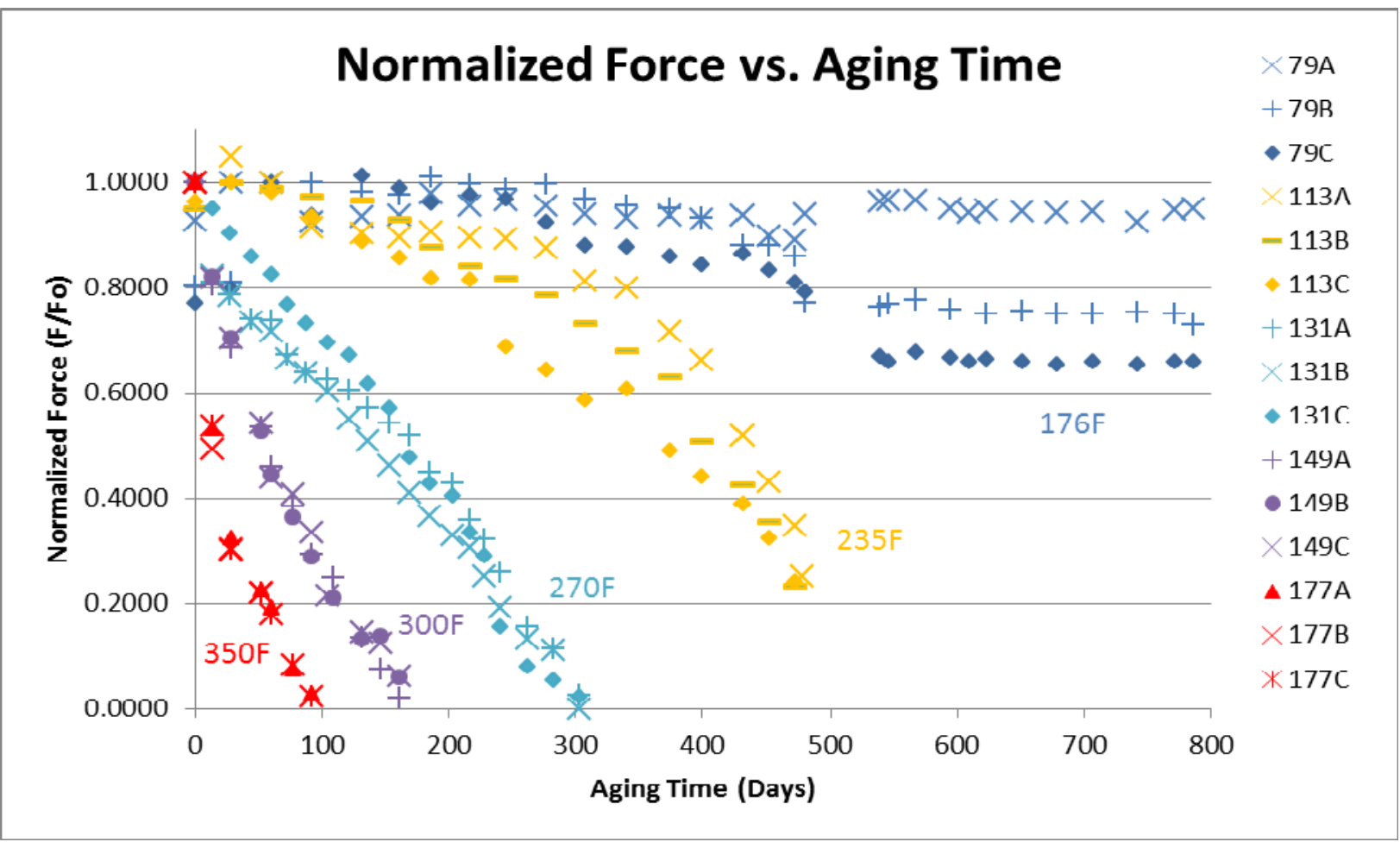

Figure 8. CSR data for the original H1616 O-ring segments at all aging temperatures

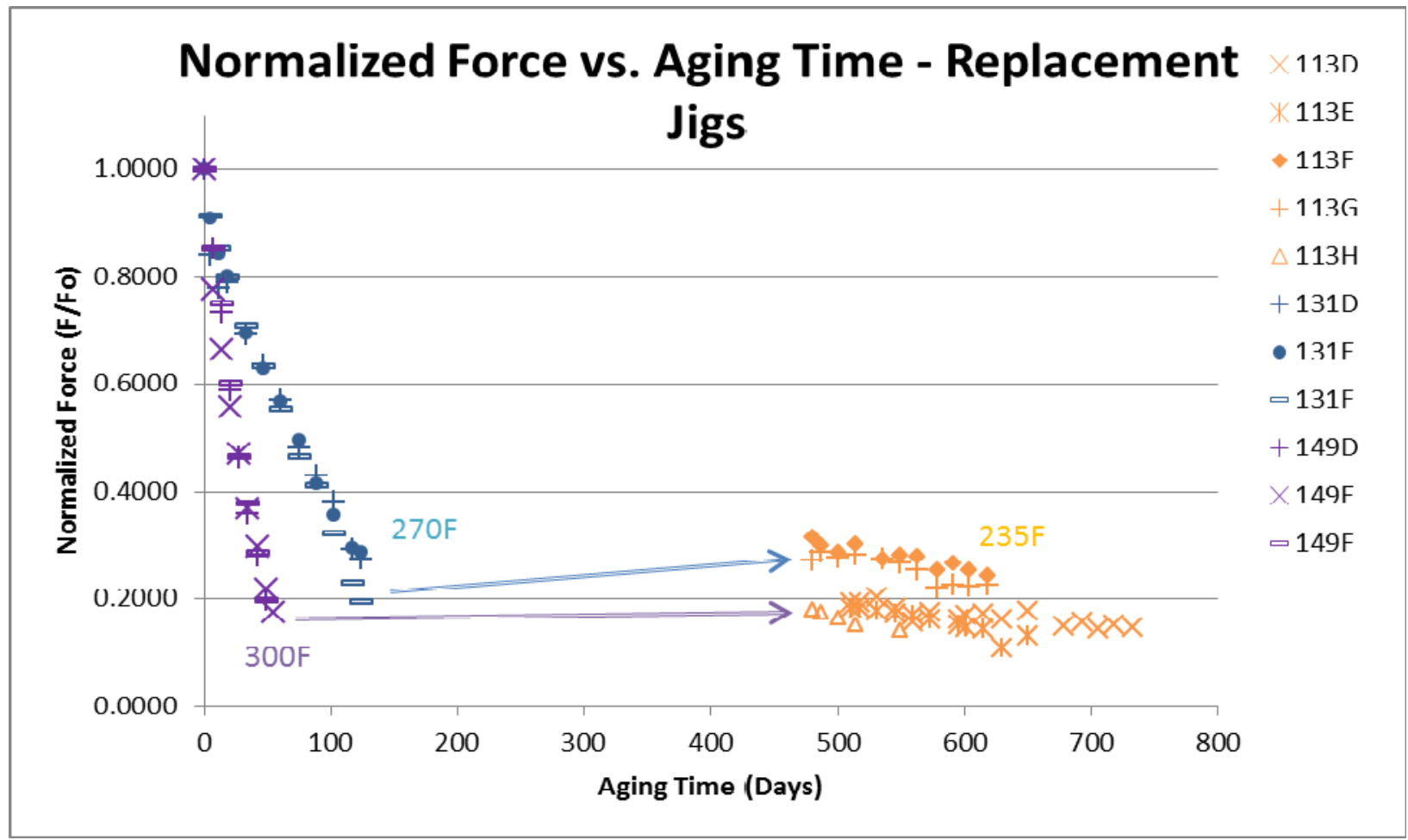

Figure 9. CSR data for the $235^{\circ} \mathrm{F}$ replacement samples, including accelerated pre-aging at 270 and $300{ }^{\circ} \mathrm{F}$. The time scale for the $235^{\circ} \mathrm{F}$ aging is shifted to align with the $235^{\circ} \mathrm{F}$ original jig data. 
Several differences are noted between Figures 8 and 9. The rates of force decay seen for 270 and $300{ }^{\circ} \mathrm{F}$ in Figure 9 are greater than for the original jigs at these temperatures in Figure 8 . The rates of force decay after the replacement samples were moved to $235^{\circ} \mathrm{F}$ are less than those for the original jigs just prior to the temperature excursion. The reason for these differences is unknown, but the reduced rates for the replacement samples at $235^{\circ} \mathrm{F}$ may be an artifact of the higher temperature pre-aging of these samples.

\section{Additional O-ring aging mechanical tests}

The primary degradation mechanism for the H1616 O-rings is expected to be thermo-oxidation, [4]. It was suspected that the argon backfill limits oxidation of the O-rings, thereby significantly extending the useful service life. As a check on this effect, two sets of O-ring segments were placed in each of the aging furnaces in order to track changes in the O-ring tensile properties and hardness (Figures 10-12). One set of these samples was exposed to air, while a second set was placed inside an enclosed container backfilled with argon. These containers consist of stainless steel tubing sealed with Swagelok fittings, to allow periodic opening for testing. This test approach provides common test parameters that can be verified following aging in each atmosphere (argon, air) for a direct identification of the impact of oxidation.

These tests indicate that an argon backfill can significantly reduce the degradation rate of the Orings, which is intuitive. While this behavior suggests that the O-ring performance in service life is likely extended compared to O-rings aged in air, the extent to which this behavior can be credited has not been determined.

In addition to the two sets of samples, six baseline (non-aged) O-ring samples were tested, with tensile strength ranging from 1637 to $\geq 2267 \mathrm{psi}$, and elongation ranging from 246 to $\geq 413$ percent. Figures 11 and 12 indicate the tensile strength and the percentage of elongation on samples aged at $175,235,300$ and $350^{\circ} \mathrm{F}$.

The tensile strength and elongation for O-rings aging at 300 and $350{ }^{\circ} \mathrm{F}$ decreased significantly faster than the O-rings aging at 235 and $175^{\circ} \mathrm{F}$, regardless of whether they were aged in air or argon.

Baseline tensile samples were initially tested with a grip arrangement in which the O-ring segment passed over a rounded mandrel to reduce the stress where the sample was gripped. It was observed that samples aged at the higher temperatures quickly became too stiff to wrap around the mandrel without breaking. Therefore, an alternate arrangement was developed and used for all aged samples. The ends of the sample were placed within multiple layers of thin flexible tube, and then placed between the faces of a flat grip. The tube layers provide isolation from the rough grip face, while generating enough friction against the sample to minimize slipping. This arrangement allowed testing of aged samples without forcing the sample to flex prior to loading. It was observed that the samples which had become stiff often broke as soon as the applied load caused any appreciable straightening of the sample. The sample also typically developed numerous circumferential cracks during the tensile test. 
When a tensile sample broke in or adjacent to the grip, it was identified as potentially not achieving the true maximum load and elongation. If sufficient length remained, the sample was retested. In addition, a few samples slipped out of the grip during test - these samples were also retested. In either case, it is possible that the initial test produced cracks or other damage in the aged samples and created a bias in the subsequent results toward a lower strength / elongation. In such a case, the maximum strength and elongation values recorded for any trial on a given sample were considered a lower bound for the actual properties of that sample and are the values depicted in Figures 11 and 12 for that sample.

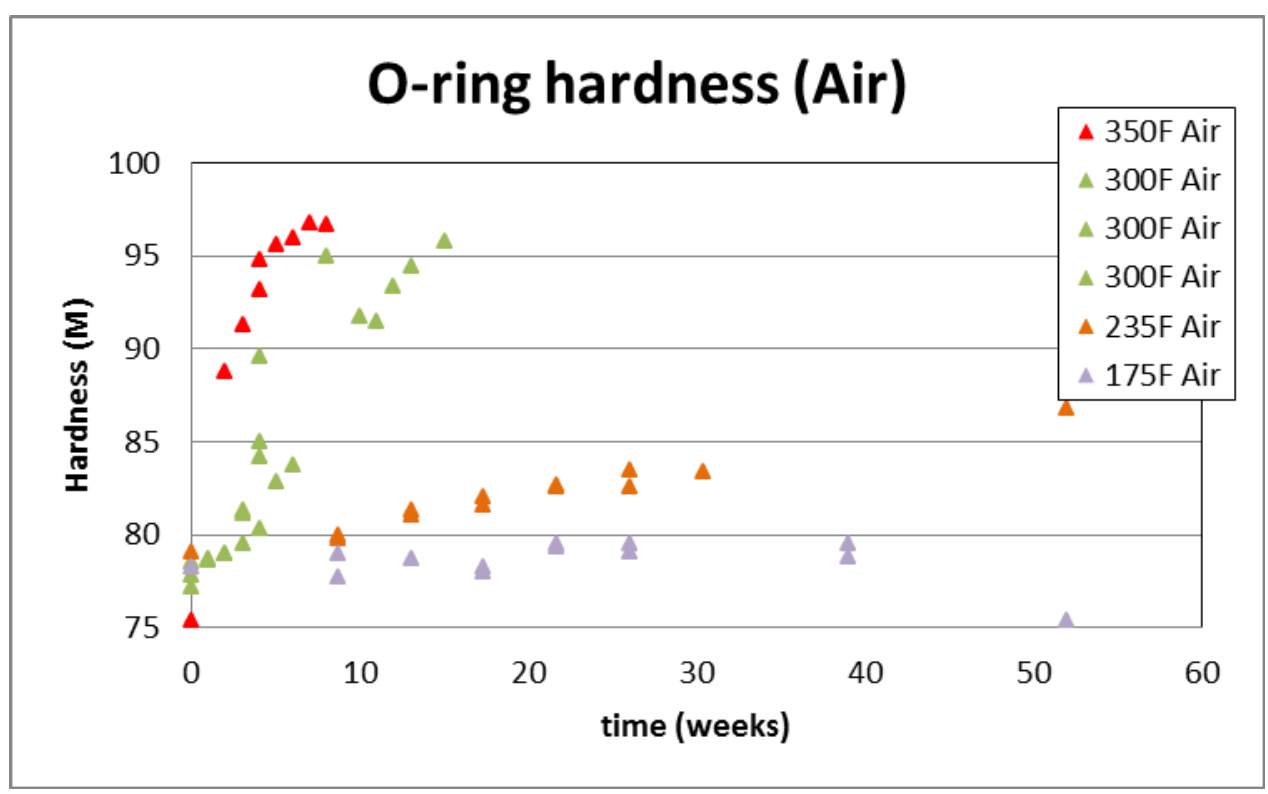

Figure 10a. Hardness of O-ring segments aged in air

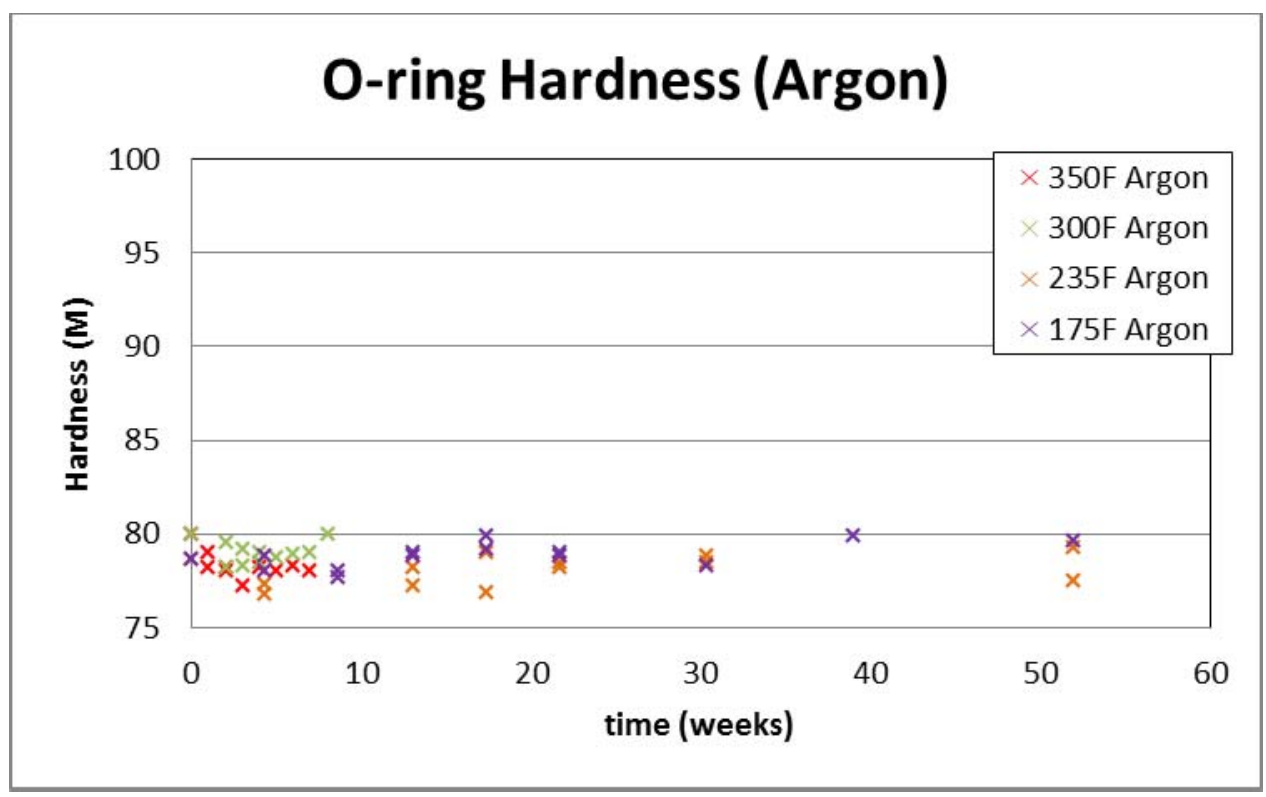

Figure 10b. Hardness of O-ring segments aged in argon 


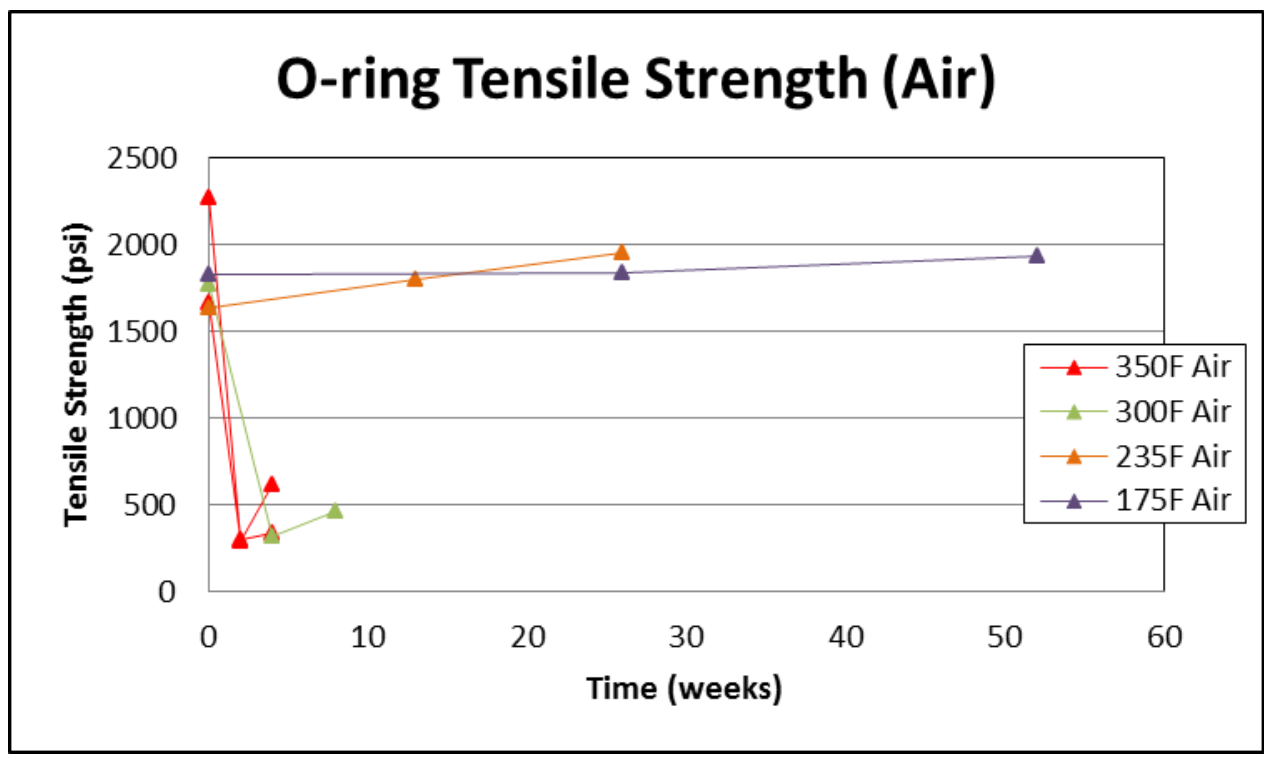

Figure 11a. Tensile strength of O-ring segments aged in air

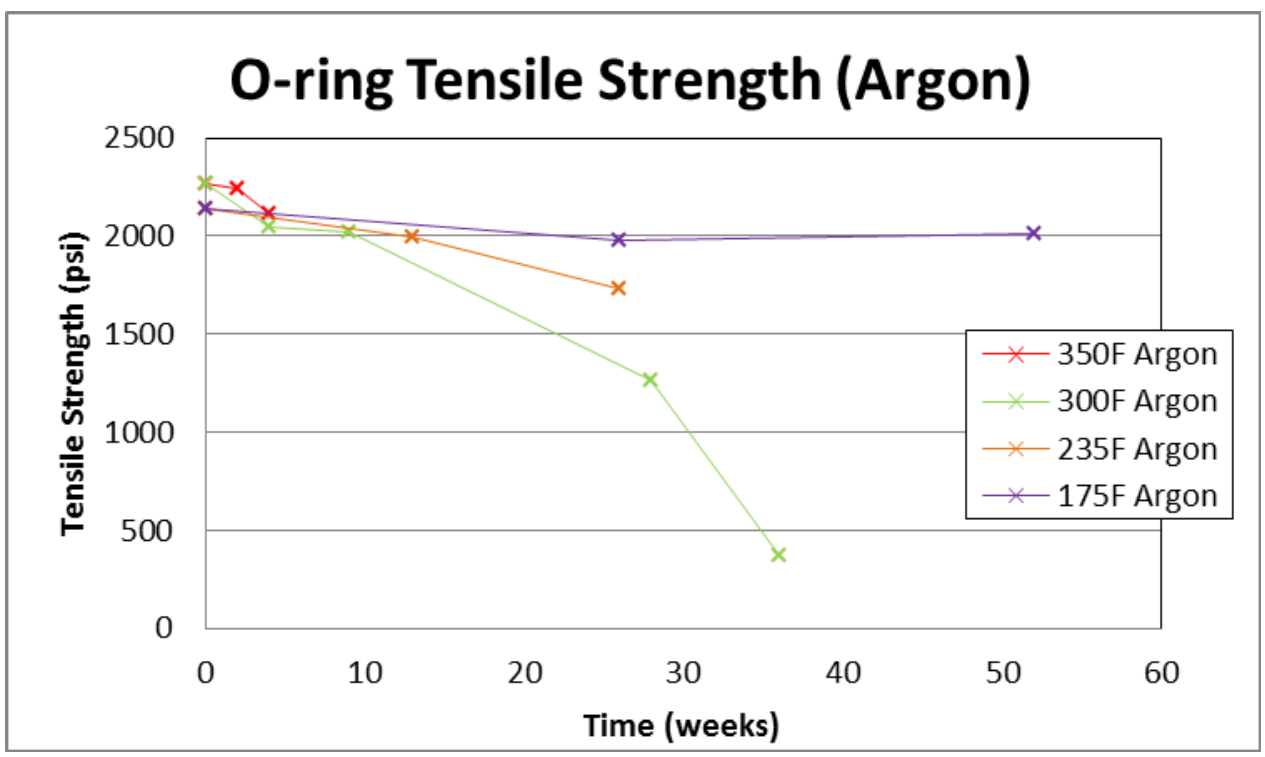

Figure 11b. Tensile strength of O-ring segments aged in argon 


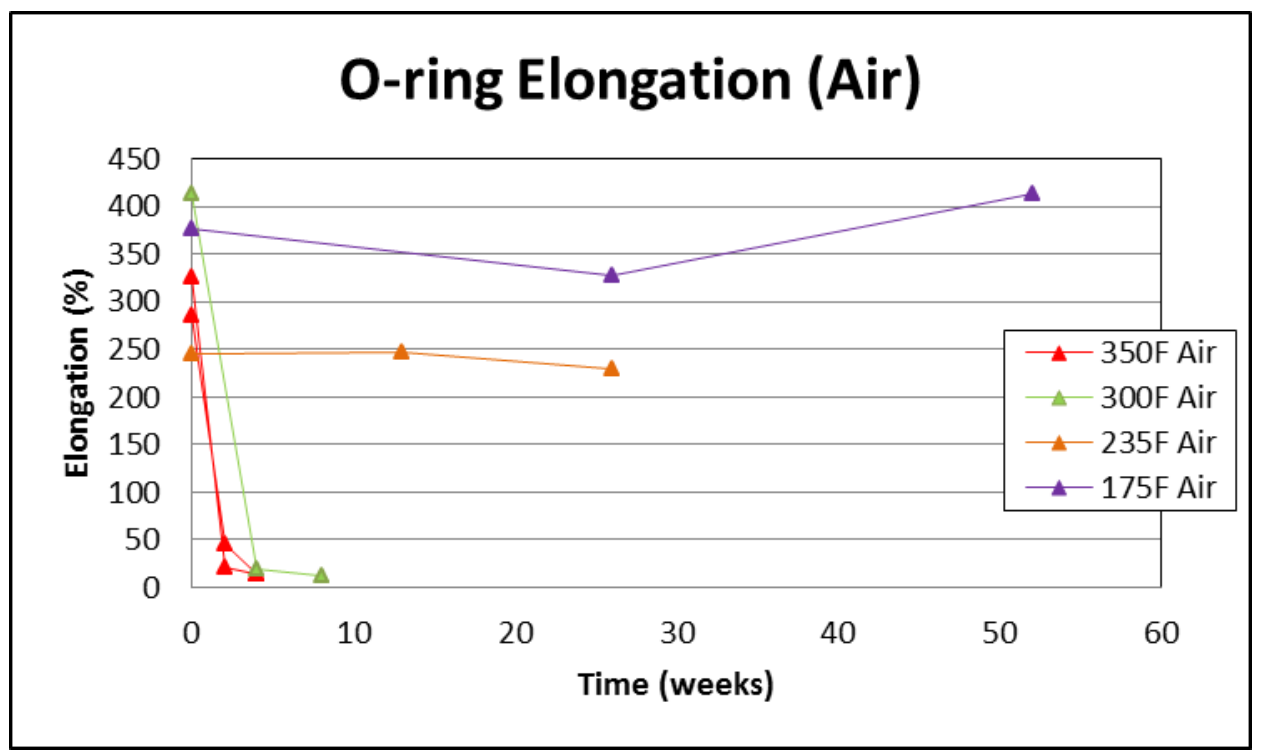

Figure 12a. Percent elongation of O-ring segments aged in air

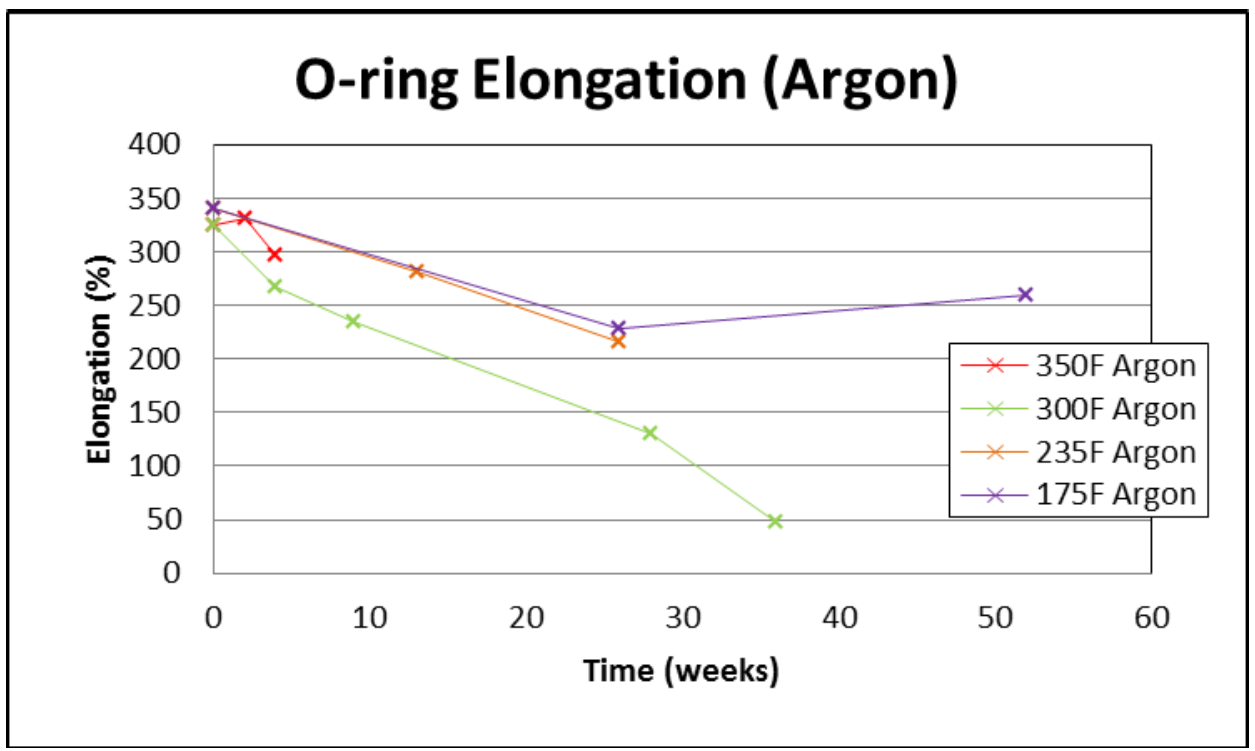

Figure $12 \mathrm{~b}$. Percent elongation of O-ring segments aged in argon

\section{SERVICE LIFE DISCUSSION}

No direct correlation has been established between CSR behavior and O-ring service life based on leak-tightness. While it is intuitive that a significantly reduced sealing force should correlate to an increased likelihood of leakage (especially for a dynamic application), very little data are available to indicate the actual sealing force needed to maintain leak-tightness. The criterion of 
$90 \%$ loss in initial sealing force has been adopted in some studies as a failure parameter, which should be a conservative limit for a relatively static seal such as the H1616 O-rings.

A further consideration in use of the CSR data in a predictive model for leak-tight service life is the test environment. The CSR samples are aged at elevated temperature in an air environment, while the vessels are maintained with an inert gas backfill, limiting the O-ring exposure to oxygen. The hardness and tensile data show a significant difference in degradation rate for the two environments (air vs argon). The O-rings are further isolated within the vessel grooves, such that there would be very little replenishment of oxygen even without an inert backfill. Even with this key difference between the CSR tests and actual service conditions, it is noted that the times to reach their respective failure criteria are relatively close: $147-162$ days for the CSR samples aging at $300{ }^{\circ} \mathrm{F}$ vs 196 days for the $300^{\circ} \mathrm{F}$ vessel to fail to maintain leak-tightness. Based on this comparison, and in the absence of a second failure point from the vessel leak tests, it is reasonable to use the CSR data in developing a predictive model for service life.

The replacement CSR samples demonstrate behavior (slope of the force decay curve) different from the original samples at the same temperatures $\left(235,270\right.$ and $\left.300^{\circ} \mathrm{F}\right)$. The slope is steeper for the replacement samples at 270 and $300^{\circ} \mathrm{F}$, and less steep at $235^{\circ} \mathrm{F}$. For each of these temperatures, restricting the data to the original samples provides a conservative basis for estimating the O-ring service life at realistic operating temperatures. The shallower slope for the replacement $235{ }^{\circ} \mathrm{F}$ data would project to a longer service time to reach $90 \%$ loss of initial sealing force, and the steeper slope at the higher temperatures gives a greater extrapolation factor, further increasing the estimated time to $90 \%$ loss of initial sealing force. Therefore, as a conservative measure, the replacement samples will not be considered in developing a service life predictive model.

Using the TTS principle, the normalized CSR data can be superposed into a "master" curve using shift factors empirically determined to achieve the best curve fit possible. Each shift factor describes the relative difference in degradation rate between two aging temperatures. The shift factors can be used to estimate the time to failure for any other temperature, so long as the same degradation mechanism(s) remain dominant over the extrapolation range. It is noted from Figure 8 that the relative shape of the sealing force decay curve varies. The lower temperature curves are convex, while the higher temperature curves are slightly concave. This suggests that different mechanisms are active in the two temperature regions, and the data from these regions should be treated separately.

The CSR data are re-plotted in Figure 13, with the time scale for each aging temperature adjusted by the shift factor identified. These shift factors were selected to provide the best agreement at the failure criterion ( $10 \%$ retained sealing force). The data for the two temperature regions are plotted separately, with the $270^{\circ} \mathrm{F}$ data plotted with both sets. The $270{ }^{\circ} \mathrm{F}$ data agree slightly better with the higher temperature data than with the lower temperature data. Since the lower temperature data are described by a lower slope without inclusion of the $270{ }^{\circ} \mathrm{F}$ data, and the lower slope provides a conservative extrapolation to service temperatures, the slope is calculated from the 175 and $235^{\circ} \mathrm{F}$ data only.

Master TTS curves are shown in Figure 13 for two reference temperatures (175 and $270{ }^{\circ} \mathrm{F}$ ), each with a shift factor of 1.0 . The $175^{\circ} \mathrm{F}$ reference temperature curve would be used to 
extrapolate to lower temperatures, while the $270{ }^{\circ} \mathrm{F}$ reference temperature curve would be relevant to higher temperatures.

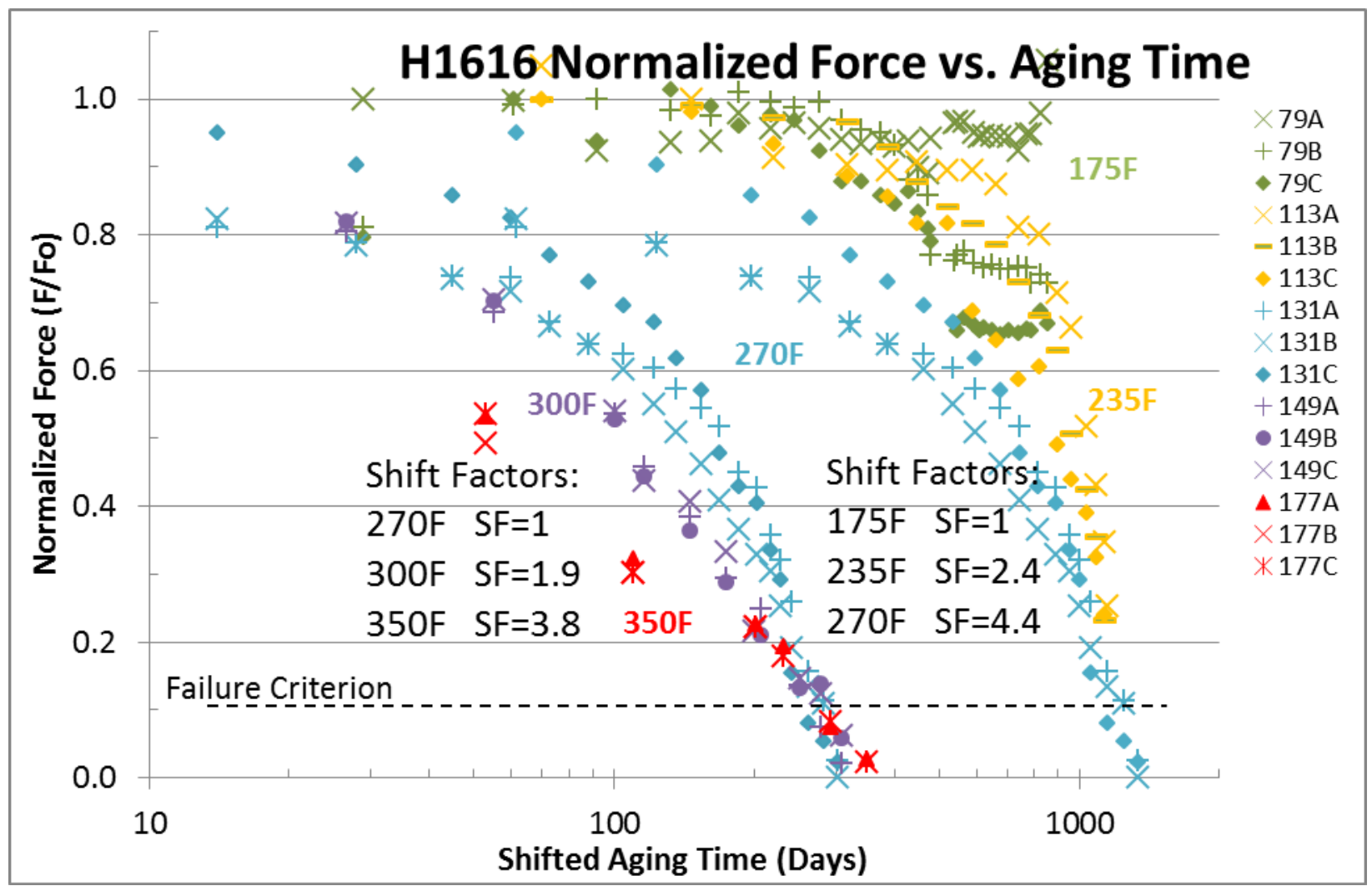

Figure 13. CSR data from Figure 8, with data for each temperature adjusted by the shift factor to provide the best agreement at the failure criterion. Higher temperature data are shifted to a reference temperature of $270{ }^{\circ} \mathrm{F}$, while lower temperature data are shifted to a reference temperature of $175^{\circ} \mathrm{F}$.

Each shift factor represents the relative difference in time scale between the average degradation rate at that temperature and the reference temperature. Together, they provide a means for extrapolating CSR behavior to other temperatures (Figure 14), assuming they follow an Arrhenius relationship. The Arrhenius relationship is described by the equation:

$$
\begin{aligned}
& \mathrm{t}=\mathrm{A} \exp \left(-\mathrm{E}_{\mathrm{a}} / \mathrm{RT}\right) \\
& \text { where } \mathrm{t}=\text { time to reach failure criterion } \\
& \mathrm{A}=\text { constant } \\
& \mathrm{E}_{\mathrm{a}}=\text { activation energy } \\
& \mathrm{R}=\text { ideal gas constant, } 8.3145 \mathrm{~J} / \mathrm{K}-\mathrm{mol} \\
& \mathrm{T}=\text { absolute temperature }(\mathrm{K})
\end{aligned}
$$




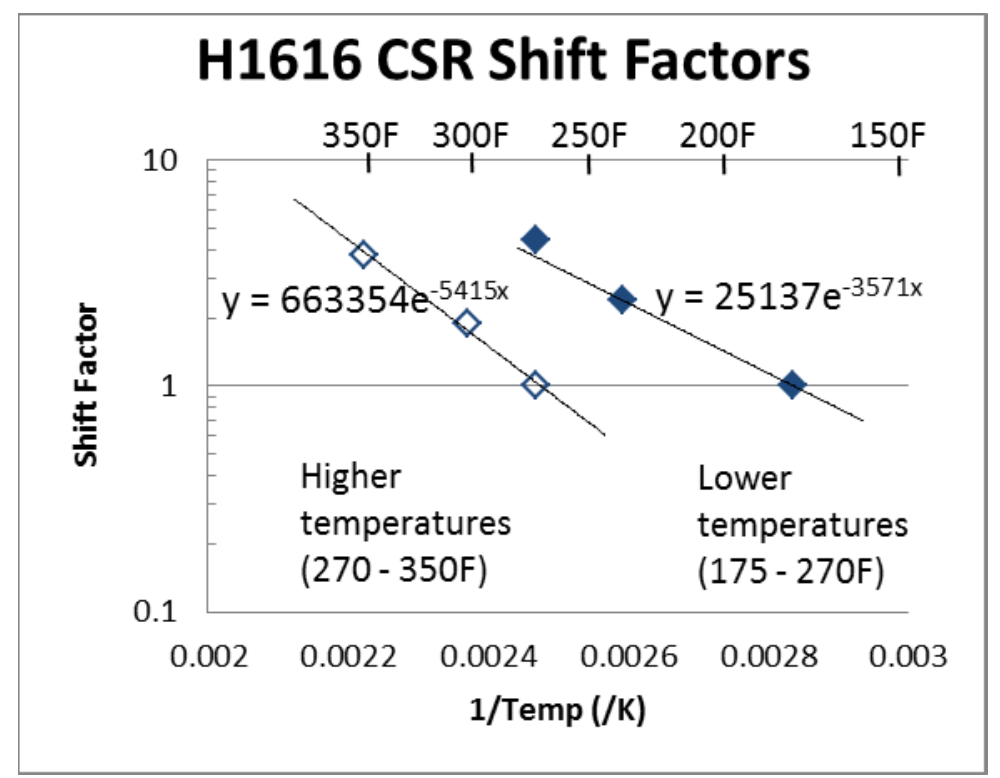

Figure 14. Shift factors vs. inverse temperature.

The slope provided by the shift factors in Figure 14 can be used to calculate the activation energy: slope $*$ ideal gas constant $=$ activation energy, or $5415 \mathrm{~K} * 8.3145 \mathrm{~J} / \mathrm{K}-\mathrm{mol}=45000$ $\mathrm{J} / \mathrm{mol}$ for temperatures above $270^{\circ} \mathrm{F}$, and $29700 \mathrm{~J} / \mathrm{mol}$ for lower temperatures. In a case of varying activation energy, extrapolations from one temperature regime to another would not be valid without adjusting for the change in activation energy at the appropriate transition temperature. The time to failure can be calculated for any temperature below $270{ }^{\circ} \mathrm{F}$ with the following Arrhenius relationship.

$$
\text { Time to failure }=3.3 \text { years } * \exp \left(-3571 *\left(0.00284-1 / \mathrm{T}_{2}(\mathrm{~K})\right)\right)
$$

With this relationship, the following estimates are made:

\begin{tabular}{|l|l|}
\hline Temperature of Interest & Estimated Time to Failure \\
\hline $235^{\circ} \mathrm{F}$ & 1.4 years \\
\hline $160^{\circ} \mathrm{F}$ & 4.2 years \\
\hline $152^{\circ} \mathrm{F}$ & 4.8 years \\
\hline
\end{tabular}

It is emphasized that these times require chronic exposure at the stated temperature, which is conservative to a typical shipping/transport application.

In the above analysis, it was assumed that the times for the CSR samples to reach the failure criterion are representative of the leak-tight service life of the H1616 vessel. This assumption can be examined at two temperatures. The estimated times to failure at $300{ }^{\circ} \mathrm{F}$ (153 days) and $235^{\circ} \mathrm{F}$ (1.4 years) based on the CSR model are less than that demonstrated by the vessel leak testing (196 days and $>2$ years, respectively). Within this temperature range, the CSR-based 
service life model is conservative to actual leak-tight behavior. However, without additional vessel failure data, the degree of conservatism at lower temperatures cannot be assessed.

The CSR data suggest that the Arrhenius relationship does not work between the two temperature regimes (above and below $\sim 270{ }^{\circ} \mathrm{F}$ ) due to changing degradation mechanisms. This has been observed in a similar EPDM compound [8]. In that case, a reduction in activation energy was observed based on oxygen consumption testing. The primary difference between the EPDM compounds is the raw EPDM polymer. The Reference 8 authors also noted that nonArrhenius aging behavior was indicated for the similar EPDM compound below $111^{\circ} \mathrm{C}\left(232^{\circ} \mathrm{F}\right)$. The 34\% decrease in activation energy suggested by the H1616 tests is very close to the 30\% decrease in activation energy reported in Reference 8. It is noted that the Reference 6 data produce a service life estimate for that compound of approximately 40 years at $152{ }^{\circ} \mathrm{F}$. The cause of variation in lifetimes predicted for the two different EPDM compounds at the same temperature $\left(152^{\circ} \mathrm{F}\right)$ is unknown, but caution is advised when making such comparisons that are based on different analytical techniques. In either case, it is important to recognize that the lifetimes predicted at peak, bounding temperatures are considered to be highly conservative.

\section{CONCLUSIONS}

Aging data for EPDM elastomers reviewed and developed within this task demonstrate that the H1616 O-rings should remain functional for at least 2 years at bounding service conditions. A conservative interpretation of the data cited in the literature review suggests that the $\mathrm{H} 1616 \mathrm{O}-$ rings can have lifetimes of 6 years at $152^{\circ} \mathrm{F}$, the maximum temperature at the flange closest to the O-rings with solar heating at $100^{\circ} \mathrm{F}$ ambient. This temperature is conservative relative to typical O-ring temperatures in service.

Baseline characterization was limited to physical and mechanical properties, namely hardness, thickness, tensile strength and elongation. These properties are consistent with O-ring specifications. The hardness and tensile properties degrade as the material ages, as expected. In addition, this degradation occurs significantly faster in an air environment than when the material is maintained in an inert atmosphere.

Leak testing has demonstrated acceptable leak-tight performance up to the two year mark for the $160{ }^{\circ} \mathrm{F}$ and $235^{\circ} \mathrm{F}$ vessels, and the continued ability to reseal at that time. The vessel aging at $300^{\circ} \mathrm{F}$ maintained leak-tightness and the capability to reseal after 174 days, however it would not reseal after 196 days. Following failure of the O-rings aging in the $300{ }^{\circ} \mathrm{F}$ vessel, new Orings were installed and began aging without an argon backfill. This was intended to demonstrate the extent to which air exposure might influence O-ring degradation. These O-rings remained leak-tight and capable of re-sealing after 193 days. With the limited free space in the O-ring groove and the close fit between the vessel and lid, it is reasonable to assume that the Orings are sufficiently isolated from a renewed oxygen source to behave similarly to O-rings in an inert atmosphere. Accordingly, the behavior of the O-rings in service is expected to be much more similar to that observed in an inert environment than in fresh air (as in CSR testing). 
CSR test samples aging at 270,300 and $350^{\circ} \mathrm{F}$ in an air environment reached a failure condition after about 40, 22 and 11 weeks, respectively. Significant degradation was also observed at 235 ${ }^{\circ} \mathrm{F}$, but the failure condition ( $90 \%$ loss in initial sealing force) was not yet reached. An aging model based on these collective data was developed to predict the O-ring behavior at service conditions. Based on this model, the H1616 O-ring service life at a bounding temperature of 152 ${ }^{\circ} \mathrm{F}$ is conservatively estimated to be $\sim 5$ years. A definitive correlation between CSR behavior and leak-tight performance has yet to be demonstrated.

The data and analysis developed within this task have produced several estimates of the service life of EPDM O-rings in the H1616 vessel:

- Literature data suggest a conservative service life of $\sim 6$ years at $152^{\circ} \mathrm{F}$.

- The CSR data (in air) indicate a service life of $\sim 5$ years at $152^{\circ} \mathrm{F}$.

- Vessel aging tests have shown leak-tight performance for 2 years at 160 and $235^{\circ} \mathrm{F}$, but these tests have not been continued to a failure condition.

It is expected that leak-tight performance of the O-rings will be significantly longer at service temperatures $\left(152{ }^{\circ} \mathrm{F}\right.$ and below) than at $235^{\circ} \mathrm{F}$. The vessel tests have demonstrated that the model predictions based on CSR data are conservative relative to actual leak performance at 235 and $300{ }^{\circ} \mathrm{F}$, although no correlation has been established to compare these two approaches at lower temperatures. Nevertheless, these collective data demonstrate that the EDPM O-rings in the H1616 vessel are fully capable of providing leak-tight performance for a period of 2 years at service temperatures of $152^{\circ} \mathrm{F}$ and below. After 2 years at temperature, the CSR data show a minimum $65 \%$ retained sealing force at $175{ }^{\circ} \mathrm{F}$, indicating a significant degree of margin to leakage failure. An even greater margin would be expected at service temperatures $\left(152^{\circ} \mathrm{F}\right)$. Therefore, an extension in the maintenance interval for the H1616 package to 2 years is recommended. The data also provide high confidence that a longer service life, possibly 5 years or longer, would likely be supported by further testing.

If an increase in the maintenance interval beyond 2 years is desired, the following additional testing is recommended:

- Continue the vessel aging / leak tests at 160 and $235^{\circ} \mathrm{F}$ (to failure and/or up to 5 years)

- Perform additional vessel aging / leak tests at 270 and $350{ }^{\circ} \mathrm{F}$ to develop additional failure points based on leak-tight performance

- $\quad$ Continue the CSR tests at 175 and $235^{\circ} \mathrm{F}$ (to failure and/or up to 5 years)

\section{ACKNOWLEDGEMENTS}

The authors gratefully acknowledge the contributions of Carla Loftin, Doug Holiday, Glenn Chapman and Greg Sides for their efforts toward test conduct and data collection. In addition, Luke Olson and Don Trapp assisted with the data acquisition system set up and leak test methodology. 


\section{REFERENCES}

[1] SRNL-STI-2011-00506, "Task Technical and Quality Assurance Plan for the Aging Studies of EPDM O-ring Material used in the H1616 Containers (U)", T.M. Stefek, T.E. Skidmore, August 2011.

[2] SAND91-2205-4, Revision 3, "Safety Analysis for the Type B (U) H1616 Reservoir Packages (U)", Sandia National Laboratory, November 2006.

[3] ANSI Standard N14.5-97, "American National Standard for Radioactive Materials Leakage Tests on Packages for Shipment”, American National Standards Institute, New York, NY, February 1998.

[4] SRNL-STI-2012-00149, "Review of Aging Data on EPDM O-rings in the H1616 Shipping Package (U)", T.E. Skidmore, March 2012.

[5] SAND2007-3076, "Supplemental Report for Recertification of the H1616 Packaging", M. Hanna, R. Gilbert-O’Neil, May 2007

[6] "Seal life of EPDM O-rings at high temperature determined by unique method", R. Marlier, R. Andre, P. Malesys, H. Issard, Journal of Packaging, Transport, Storage \& Security of Radioactive Materials, 2006, Vol.17, No.1

[7] Polymer Degradation and Stability 82 (2003) 25-35 "Validation of improved methods for predicting long-term elastomeric seal lifetimes from compression stress-relaxation and oxygen consumption techniques”, K.T. Gillen, M Celina, R. Berstein, March 2003

[8] SAND98-1942, "New Methods for Predicting Lifetimes in Weapons Part 1: Ultrasensitive Oxygen Consumption Measurements to Predict the Lifetime of EPDM O-Rings", K.T. Gillen, M. Celina, R.L. Clough, G.M. Malone, M.R. Kennan, J. Wise, Sandia National Laboratory, September 1998 
CC: K. G. Aylward, 235-H

J. S. Bellamy, 730-A

R. L. Bickford, 730-A

P. S. Blanton, 730-A

D. B. Carroll, 235-H

G. T. Chandler, 773-A

W. L. Daugherty, 773-A

B. K. Damkroger, Sandia National Lab

K. A. Dunn, 773-41A

P. J. French, 234-H

E. L. Hamilton, 773-42A

D. M. Hasty, 719-H

K. J. Imrich, 773-A

C. R. Johnson, 719-H

T. M. Stefek, 773-41A

T. E. Skidmore, 730-A

C. F. Swanson, 235-H

T. D. Woodsmall, 235-H

K. E. Zeigler, 773-41A

Document Control 